\title{
Krüppel-homolog 1 exerts anti- metamorphic and vitellogenic functions in insects via phosphorylation-mediated recruitment of specific cofactors
}

\author{
Zhongxia Wu, Libin Yang, Huihui Li and Shutang Zhou* (D)
}

\begin{abstract}
Background: The zinc-finger transcription factor Krüppel-homolog 1 (Kr-h1) exerts a dual regulatory role during insect development by preventing precocious larval/nymphal metamorphosis and in stimulating aspects of adult reproduction such as vitellogenesis. However, how $\mathrm{Kr}$-h1 functions both as a transcriptional repressor in juvenile metamorphosis and an activator in adult reproduction remains elusive. Here, we use the insect Locusta migratoria to dissect the molecular mechanism by which $\mathrm{Kr}$-h1 functions as activator and repressor at these distinct developmental stages.

Results: We report that the kinase PKCa triggers Kr-h1 phosphorylation at the amino acid residue $\mathrm{Ser}^{154}$, a step essential for its dual functions. During juvenile stage, phosphorylated Kr-h1 recruits a corepressor, C-terminal binding protein (CtBP). The complex of phosphorylated $\mathrm{Kr}-\mathrm{h} 1$ and $\mathrm{CtBP}$ represses the transcription of Ecdysone induced protein $93 \mathrm{~F}$ (E93) and consequently prevents the juvenile-to-adult transition. In adult insects, phosphorylated $\mathrm{Kr}$-h1 recruits a coactivator, CREB-binding protein (CBP), and promotes vitellogenesis by inducing the expression of Ribosomal protein L36. Furthermore, Kr-h1 phosphorylation with the concomitant inhibition of E93 transcription is evolutionarily conserved across insect orders.
\end{abstract}

Conclusion: Our results suggest that Kr-h1 phosphorylation is indispensable for the recruitment of transcriptional cofactors, and for its anti-metamorphic and vitellogenic actions in insects. Our data shed new light on the understanding of $\mathrm{Kr}$-h1 regulation and function in $\mathrm{JH}$-regulated insect metamorphosis and reproduction.

Keywords: Kr-h1, Juvenile hormone, E93, Insect metamorphosis, Female reproduction

\section{Background}

Juvenile hormone $(\mathrm{JH})$, an arthropod-specific sesquiterpenoid secreted by the corpora allata, plays a central role in insect metamorphosis and reproduction. In juvenile stages, $\mathrm{JH}$ maintains the larval/nymphal status by suppressing the metamorphic action of the steroid hormone 20-hydroxyecdysone (20E) [1-5]. In adult insects, JH

\footnotetext{
* Correspondence: szhou@henu.edu.cn

State Key Laboratory of Cotton Biology, Key Laboratory of Plant Stress Biology, School of Life Sciences, Henan University, Kaifeng 475004, China
}

stimulates aspects of reproduction including postemergence development, vitellogenesis, and oogenesis $[6,7]$. Krüppel-homolog $1(K r-h 1)$ is a primary JH earlyinducible gene coding for a zinc-finger transcription factor that mediates both anti-metamorphic and vitellogenic actions of $\mathrm{JH}$ [8-11]. Kr-h1 prevents immature larvae from precocious larval-pupal metamorphosis by inhibiting the transcription of pupa-specifier gene Broad-complex $(\mathrm{Br}-\mathrm{C})$ in holometabolous insects [1214]. Kr-h1 also prevents precocious nymphal-adult or

(c) The Author(s). 2021 Open Access This article is licensed under a Creative Commons Attribution 4.0 International License, which permits use, sharing, adaptation, distribution and reproduction in any medium or format, as long as you give appropriate credit to the original author(s) and the source, provide a link to the Creative Commons licence, and indicate if changes were made. The images or other third party material in this article are included in the article's Creative Commons licence, unless indicated otherwise in a credit line to the material. If material is not included in the article's Creative Commons licence and your intended use is not permitted by statutory regulation or exceeds the permitted use, you will need to obtain permission directly from the copyright holder. To view a copy of this licence, visit http://creativecommons.org/licenses/by/4.0/ The Creative Commons Public Domain Dedication waiver (http://creativecommons.org/publicdomain/zero/1.0/) applies to the data made available in this article, unless otherwise stated in a credit line to the data. 
pupal-adult transition by inhibiting the expression of $E c$ dysone induced protein $93 F$ (E93), an adult-specifier gene in both hemimetabolous and holometabolous insects [14-17] in the context of the MEKRE93 pathway, the general regulatory axis of insect metamorphosis $[8,15]$. In addition, $\mathrm{Kr}-\mathrm{h} 1$ suppresses $20 \mathrm{E}$ biosynthesis by inhibiting the expression of steroidogenic enzyme gene Spok in prothoracic glands of the fruit fly Drosophila melanogaster and thus prevents precocious larval-pupal transformation [18]. Stimulation of female reproduction by $\mathrm{Kr}-\mathrm{h} 1$ is reported in a variety of insect species $[9,10$, 19]. RNAi-mediated knockdown of $K r-h 1$ resulted in blocked vitellogenesis and impaired egg development in the migratory locust Locusta migratoria, the rice borer Chilo suppressalis, the oriental fruit fly Bactrocera dorsalis, the cotton bollworm Helicoverpa armigera, and the brown planthopper Nilaparvata lugens [20-24]. In the mosquito Aedes aegypti, Kr-h1 regulates the developmental phase in preparation for competence acquisition for blood feeding, as well as subsequent vitellogenesis and egg development [25-27]. In the common bed bug Cimex lectularius, depletion of $\mathrm{Kr}$ - $h 1$ in adult females caused severely reduced egg hatchability [28].

$\mathrm{Kr}$ - $\mathrm{h} 1$ is transcriptionally activated by the JH-receptor complex comprising Methoprene-tolerant (Met) and Taiman, two members of the bHLH-PAS transcription factor family [15, 29-33]. Met also dimerizes with Cycle, which upregulates $K r$ - $h 1$ transcription in $\mathrm{JH}$-mediated previtellogenic development of Ae. aegypti [25]. In the beetle Tribolium castaneum, JH represses the expression of Histone deacetylase 1 (HDAC1), leading to increased levels of histone acetylation and consequently promoting $K r-h 1$ transcription [34, 35]. Beside transcriptional regulation, $K r-h 1$ is post-transcriptionally regulated by microRNAs $[19,36]$. In the cockroach Blattella germanica, miR-2 eliminates $K r-h 1$ transcripts at final instar nymphs, which crucially contributes to the onset of metamorphosis [37]. In L. migratoria, $K r-h 1$ is downregulated by let- 7 and miR-278, whereas $\mathrm{JH}$ suppresses the expression of these two miRNAs. This regulatory loop ensures a proper level of $\mathrm{Kr}$-h1 essential for preventing precocious metamorphosis in nymphs and stimulating $\mathrm{JH}$-dependent vitellogenesis in adults [38-44].

In an effort to elucidate how $\mathrm{Kr}$-h1 functions in repressing precocious nymph metamorphosis and stimulating adult reproduction in L. migratoria, we investigated $\mathrm{Kr}-\mathrm{h} 1$ phosphorylation and its involvement in transcriptional repression and activation. The migratory locust L. migratoria is a destructive insect pest worldwide as well as a representative of evolutionarily basal insects with hemimetabolous development and $\mathrm{JH}-$ dependent vitellogenesis. We found that PKC $\alpha$ triggers $\mathrm{Kr}$-h1 phosphorylation. Phosphorylated $\mathrm{Kr}-\mathrm{h} 1$ recruited C-terminal binding protein (CtBP), consequently inhibiting E93 expression and nymphal-adult metamorphosis. Phosphorylated $\mathrm{Kr}$-h1 interacted with CREBbinding protein (CBP), which stimulated the transcription of Ribosomal protein L36 (RL36) and reproduction. We also provide evidence that the essential role of phosphorylated $\mathrm{Kr}-\mathrm{h} 1$ in recruiting CtBP and repressing E93 expression is evolutionarily conserved in other representative insects including the silkworm Bombyx mori, the beetle $T$. castaneum and the fruit fly $D$. melanogaster.

\section{Results}

$\mathrm{Kr}$-h1 is phosphorylated by PKCa at Ser ${ }^{154}$

We initially predicted the phosphorylation of L. migratoria Kr-h1 (GenBank: KJ425482) computationally by DISPHOS (V1.3) software [45]. Three serine residues, $\mathrm{Ser}^{154}, \mathrm{Ser}^{371}$, and $\mathrm{Ser}^{554}$ were suggested as potential phosphorylation sites, with $\operatorname{Ser}^{154}$ at the highest score (Additional file 1: Fig. S1A). To validate $\mathrm{Kr}-\mathrm{h} 1$ phosphorylation, we performed immunoprecipitation using a commercial anti-phospho-(Ser) antibody and a polyclonal anti-Kr-h1 antibody [38]. Phosphorylated Kr-h1 (p-Kr-h1) was detected in protein extracts from both nymphs and adults (Additional file 1: Fig. S1B). We generated an anti-phospho-Kr-h1 (Ser ${ }^{154}$ ) antibody (Additional file 1: Fig. S1C). Its specificity was verified by western blot using proteins extracted from adult female fat bodies subjected to $K r$ - $h 1$ knockdown as well as those treated with phosphatase $\lambda$ pp (Fig. 1A). The specificity of anti-phospho-Kr-h1 ( $\mathrm{Ser}^{154}$ ) antibody was also verified by western blot using the recombinant Flagtagged proteins of wildtype $\mathrm{Kr}-\mathrm{h} 1$ and mutated $\mathrm{Kr}$ $\mathrm{h} 1^{\mathrm{S} 154 \mathrm{~A}}\left(\mathrm{Ser}^{154}\right.$ to $\left.\mathrm{Ala}^{154}\right)$ expressed in Drosophila S2 cells treated with methoprene as well as the bacterially expressed GST-tagged peptides of $\mathrm{Kr}-\mathrm{h} 1(\mathrm{aa} 1-290)$ and $\mathrm{Kr}-\mathrm{h} 1^{\mathrm{S} 154 \mathrm{~A}}$ (aa1-290) incubated with PKC $\alpha$ (Additional file 1: Fig. S1D). We next investigated the kinase triggering $\mathrm{Kr}$-h1 phosphorylation at Ser ${ }^{154}$. The motif KAFSVK at amino acid residues $151-156$ of L. migratoria $\mathrm{Kr}-\mathrm{h} 1$ (Additional file 1: Fig. S1A) is a conserved motif recognized by PKC [46-48], presumably PKC $\alpha$ and PKC $\eta$ as predicted by a GPS algorithm [49]. As evaluated by western blots, application of the PKC inhibitor NPC15437 in nymphs and adult females reduced p-Krh1 levels (Fig. 1B). Depletion of $P K C \alpha$ (GenBank: MT081310) in nymphs and adult females caused significant reduction of $\mathrm{p}-\mathrm{Kr}-\mathrm{h} 1$ but not total $\mathrm{Kr}-\mathrm{h} 1$ abundance (Fig. 1B and Additional file 1: Fig. S2A). In contrast, $P K C \eta$ (GenBank: MT081311) knockdown had no obvious effect on $\mathrm{Kr}$-h1 phosphorylation (Additional file 1: Fig. S2B). These results imply that PKC $\alpha$ is likely to mediate Kr-h1 phosphorylation at Ser ${ }^{154}$. To confirm the action of PKC $\alpha$ on $\mathrm{Kr}-\mathrm{h} 1$ phosphorylation, we synthesized wildtype $\mathrm{Kr}-\mathrm{h} 1$ (aa125-159) and mutated $\mathrm{Kr}$ $\mathrm{h} 1^{\mathrm{S} 154 \mathrm{~A}}$ (aa125-159) peptides, followed by incubating 


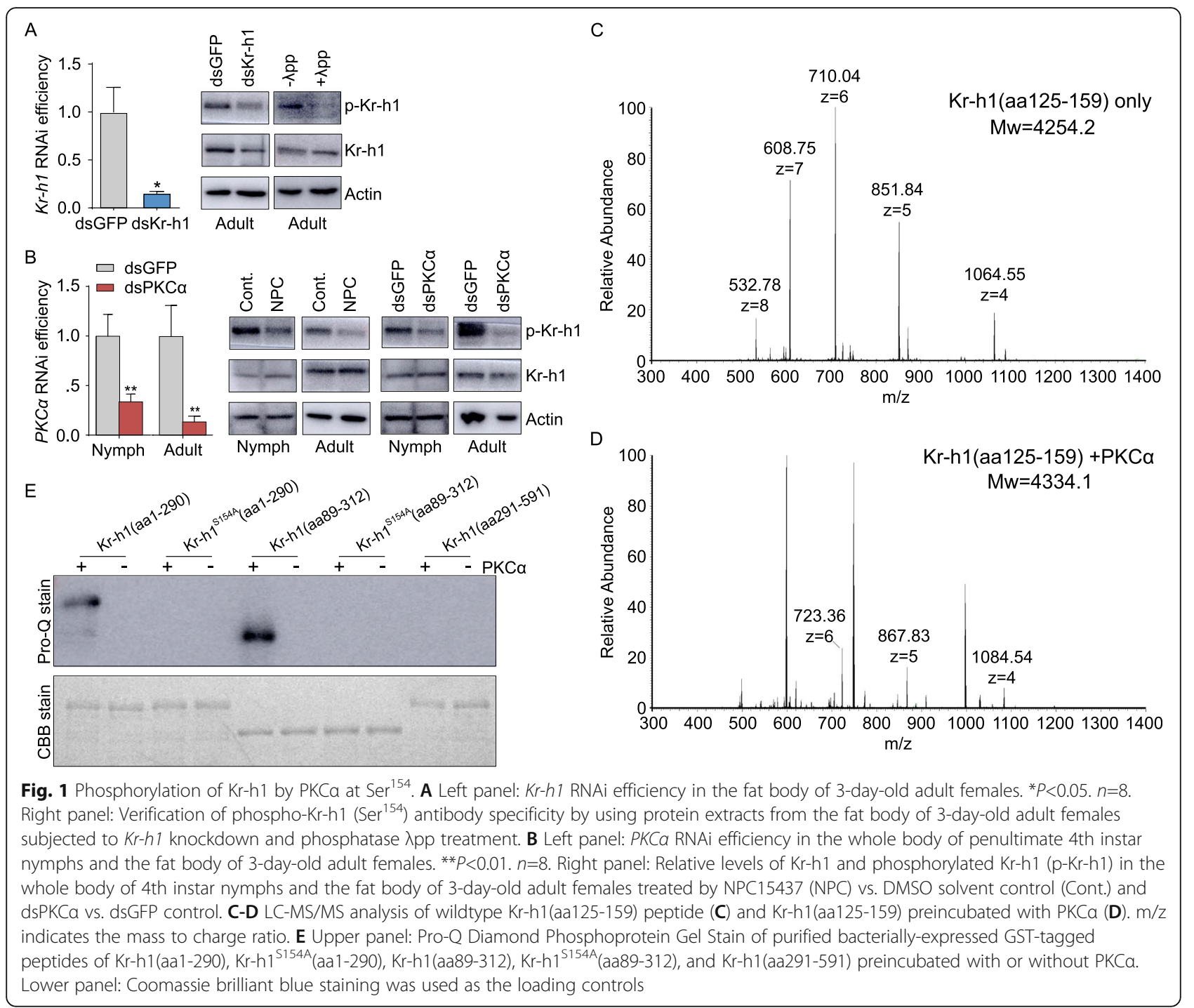

them separately with PKC $\alpha$ for LC-MS/MS analysis. As illustrated in Fig. 1C, Kr-h1(aa125-159) peptide without PKC $\alpha$ treatment had a molecular mass of 4,254 Da. However, incubation of $\mathrm{Kr}-\mathrm{h} 1$ (aa125-159) peptide with PKC $\alpha$ yielded a molecular mass of 4,334 Da (Fig. 1D), exhibiting an 80 Da shift compared to Kr-h1(aa125-159) peptide without PKC $\alpha$ treatment. When mutated $\mathrm{Kr}$ -

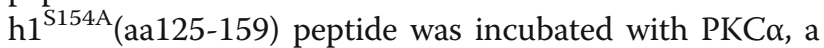
molecular mass of $4238 \mathrm{Da}$ was detected, same as that observed with $\mathrm{Kr}-\mathrm{h} 1^{\mathrm{S} 154 \mathrm{~A}}$ (aa125-159) peptide alone (Additional file 1: Fig. S2C). To further define PKC $\alpha-$ mediated $\mathrm{Kr}$-h1 phosphorylation at $\mathrm{Ser}^{154}$, we carried out Pro-Q Diamond Phosphoprotein Gel Staining with purified bacterially expressed GST-tagged peptides of

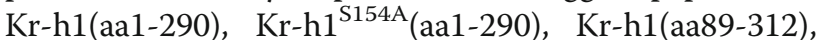
$\mathrm{Kr}-\mathrm{h} 1^{\mathrm{S} 154 \mathrm{~A}}$ (aa89-312), and $\mathrm{Kr}-\mathrm{h} 1$ (aa291-591) incubated with PKC $\alpha$. As shown in Fig. 1E, the specific phosphorylation bands were observed with wildtype Kr-h1(aa1-
290) and Kr-h1(aa89-312) peptides, but not mutated Krh1 ${ }^{\text {S154A }}$ (aa1-290) or Kr-h1 ${ }^{\text {S154A }}$ (aa89-312). No phosphorylation band was observed with the truncated $\mathrm{Kr}$ h1(aa291-591) (Fig. 1E), indicating that PKC $\alpha$-mediated $\mathrm{Kr}-\mathrm{h} 1$ phosphorylation is unlikely to occur at $\mathrm{Ser}^{371}$ or Ser ${ }^{554}$.

\section{$\mathrm{Kr}-\mathrm{h} 1$ expression and phosphorylation are in response to $\mathrm{JH}$}

To explore the dynamics of $\mathrm{p}-\mathrm{Kr}-\mathrm{h} 1$ before the onset of locust metamorphosis, we conducted western blot using proteins extracted from the penultimate 4th and final 5th instar nymphs. As shown in Fig. 2A, p-Kr-h1 levels were high in mid and late 4th instar nymphs but markedly declined in 5 th instar nymphs. The decreased levels of $\mathrm{p}-\mathrm{Kr}-\mathrm{h} 1$ at final nymphal instar appeared to correlate with the decline of $\mathrm{JH}$ titer in this phase [50], suggesting a possible effect of $\mathrm{JH}$ on $\mathrm{Kr}$-h1 phosphorylation. It 


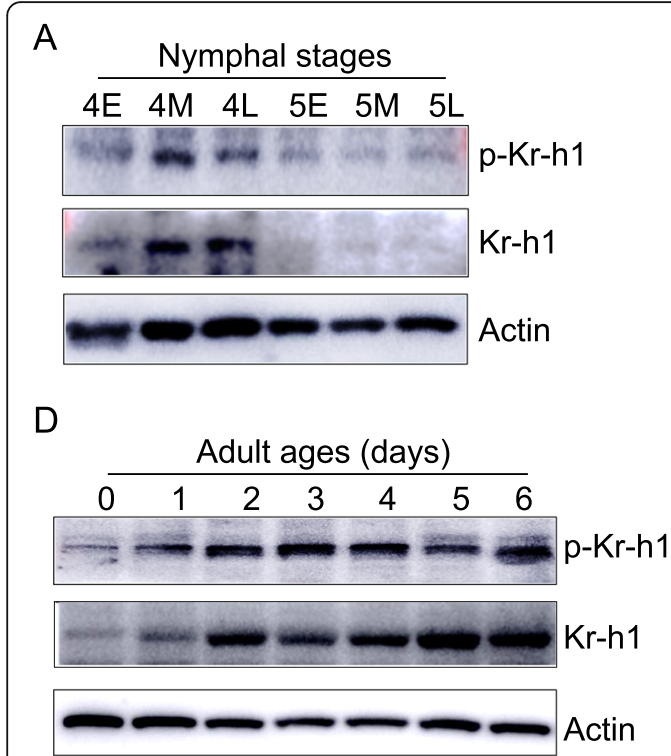

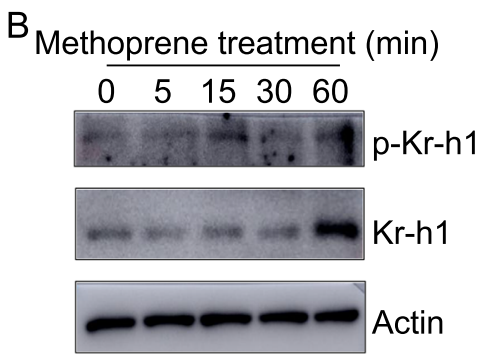

E

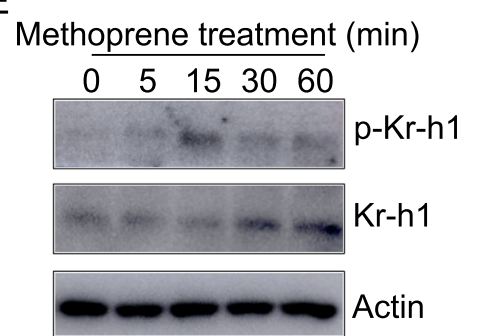

C

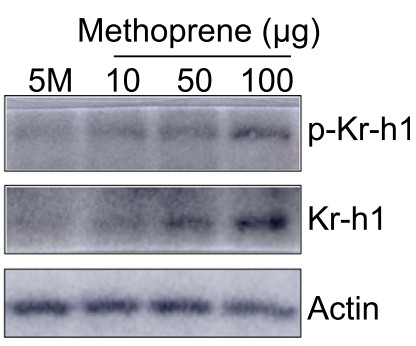

$\mathrm{F}$

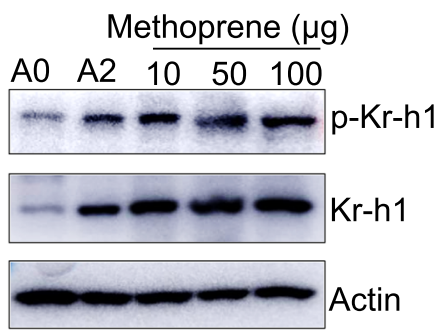

Fig. 2 Responsiveness of $\mathrm{Kr}$-h1 phosphorylation to $\mathrm{JH}$. A Abundance of $\mathrm{Kr}-\mathrm{h} 1$ and $\mathrm{p}-\mathrm{Kr}$-h1 in the whole body of penultimate 4th and final 5 th instar nymphs. E, M and L indicate the early (day 1), mid (day 2 for 4th, and day 3 for 5th), and late (day 4 for 4th, and day 5 for 5 th) stages, respectively. B Relative levels of $\mathrm{Kr}-\mathrm{h} 1$ and $\mathrm{p}-\mathrm{Kr}-\mathrm{h} 1$ in mid-5th instar nymphs and in those further treated with methoprene at $100 \mu \mathrm{g}$ per locust for 5-60 min. C Relative abundance of Kr-h1 and p-Kr-h1 in mid-5th instar nymphs (5M) and those further treated with methoprene at 10-100 $\mu \mathrm{g}$ per locust for $8 \mathrm{~h}$. D Developmental dynamics of $\mathrm{Kr}-\mathrm{h} 1$ and p-Kr-h1 in the fat body of adult females at 0-6 days post adult emergence. E Relative levels of $\mathrm{Kr}-\mathrm{h} 1$ and $\mathrm{p}-\mathrm{Kr}$-h1 in the fat body of newly-emerged adult females (A0) as well as those further treated with methoprene at $100 \mu \mathrm{g}$ per locust for 5-60 min. F Relative levels of Kr-h1 and p-Kr-h1 in the fat body of newly-emerged adult females (A0) as well as those further treated with methoprene at 10-100 $\mathrm{\mu g}$ per locust for $8 \mathrm{~h}$. A2, 2-day-old adult female as a control

should be noted that $K r-h 1$ is expressed in response to $\mathrm{JH}[21,38]$. The abundance of total Kr-h1 also decreased in 5th instar nymphs (Fig. 2A). To evaluate the responsiveness of $\mathrm{Kr}$-h1 phosphorylation to $\mathrm{JH}$ in juvenile stage, western blot was performed using protein extracts from mid-5th instar nymphs as well as those further treated with methoprene for 5-60 min. Application of methoprene caused increase of both $\mathrm{Kr}-\mathrm{h} 1$ and $\mathrm{p}-\mathrm{Kr}-\mathrm{h} 1$ levels, and longer exposure to methoprene tended to have a relatively more pronounced effect on $\mathrm{Kr}-\mathrm{h} 1$ expression and phosphorylation (Fig. 2B). Notably, p-Krh1 levels increased more rapidly than total $\mathrm{Kr}-\mathrm{h} 1$ after 15-min exposure to methoprene (Fig. 2B and Additional file 1: Fig. S3), implying a role of $\mathrm{JH}$ in stimulating $\mathrm{Kr}-\mathrm{h} 1$ phosphorylation. Dose-response experiments demonstrated that higher doses of methoprene induced higher levels of $\mathrm{Kr}-\mathrm{h} 1$ and $\mathrm{p}-\mathrm{Kr}-\mathrm{h} 1$ (Fig. 2C). The data suggest that $\mathrm{JH}$ promotes $\mathrm{Kr}-\mathrm{h} 1$ expression and phosphorylation in nymphs, and the high levels of $\mathrm{Kr}$-h1 phosphorylation are generally observed with more abundant $\mathrm{Kr}-\mathrm{h} 1$ proteins.

We next studied the temporal abundance of $\mathrm{p}-\mathrm{Kr}-\mathrm{h} 1$ after adult ecdysis using protein extracts from the fat body of adult females at $0-6$ days post adult emergence (PAE). Compared to that on the day of adult emergence, p-Kr-h1 levels increased at 1-4 days PAE and remained high on days 5-6, resembling that of total Kr-h1 (Fig.
2D). As $\mathrm{JH}$ is undetectable in the hemolymph at adult emergence but sharply increases thereafter [51], the enhanced levels of $\mathrm{Kr}-\mathrm{h} 1$ and $\mathrm{p}-\mathrm{Kr}-\mathrm{h} 1$ appeared to positively correlate with elevated hemolymph $\mathrm{JH}$ titer. To elucidate the responsiveness of $\mathrm{Kr}-\mathrm{h} 1$ phosphorylation to $\mathrm{JH}$ in adult locusts, western blot analysis was carried out using protein extracts isolated from the fat body of newly emerged adult females and those further treated with methoprene. As observed in nymphs, methopreneinduced $\mathrm{Kr}$-h1 expression and phosphorylation were also seen in adults (Fig. 2E, F). Likewise, p-Kr-h1 abundance increased more rapidly than total $\mathrm{Kr}-\mathrm{h} 1$ in the fat body of adult females treated with methoprene for $15 \mathrm{~min}$ (Fig. 2E and Additional file 1: S3). Taken together, our data suggest that $\mathrm{JH}$-induced $\mathrm{Kr}$-h1 expression is accompanied by increased levels of Kr-h1 phosphorylation in both nymphal and adult locusts.

\section{$\mathrm{Kr}-\mathrm{h} 1$ phosphorylation is required for its anti- metamorphic action}

Previous studies have documented that E93 controls metamorphic nymphal-adult or pupal-adult transition [14-16]. Kr-h1 represses E93 transcription [15] by binding to the promoter sequence bearing the core $\mathrm{Kr}-\mathrm{h} 1$ binding site (KBS) [17]. As expected, depletion of E93 (GenBank: MT081312) in the final instar nymph of locusts resulted in supernumerary nymphs and delayed 
adult morphogenesis (Additional file 1: Fig. S4). Knockdown of $K r-h 1$ in penultimate instar nymphs caused 4.5fold increase of E93 transcripts (Fig. 3A). Application of a PKC inhibitor, NPC15437, or knockdown of $P K C \alpha$ led to significant increase of E93 mRNA levels (Fig. 3A), suggesting the possible requirement of Kr-h1 phosphorylation for repressing E93 transcription. Analysis of upstream 3-kb sequence revealed a conserved KBS in the proximal promoter region (nt -617 to -612) of L. migratoria E93 gene (Additional file 1: Fig. S5A). We then carried out dual luciferase reporter assays by cotransfection of pGL4.10-4×E93 ${ }^{-623}$ to -606 with pAc5.1/ Flag-Kr-h1, pAc5.1/Flag-Kr-h1 ${ }^{\text {S154A }}$, pAc5.1/Flag-Kr$\mathrm{h} 1^{\text {S154D }}$ or pAc5.1/Flag empty control into Drosophila S2 cells treated with methoprene. Western blot demonstrated that methoprene treatment stimulated Flag-Krh1 phosphorylation (Additional file 1: Fig. S5B). Overexpression of Flag-Kr-h1 plus methoprene treatment caused about 58\% reduction of E93 reporter activity compared to the empty vector control (Fig. 3B). The capacity of $\mathrm{Kr}$-h1 to inhibit E93 reporter activity was blocked by overexpression of Flag-Kr-h1 ${ }^{\mathrm{S} 154 \mathrm{~A}}$, a mutated $\mathrm{p}-\mathrm{Kr}$-h1 (Fig. 3B). In contrast, overexpression of p-Kr-h1 wildtype variant, Flag-Kr-h1 $1^{\text {S154D }}$, restored the inhibitory constraints of $\mathrm{Kr}-\mathrm{h} 1$ on E93 reporter activity (Fig. 3B). As illustrated in Additional file 1: Fig. S5B, Flag-Kr$\mathrm{h} 1^{\mathrm{S} 154 \mathrm{D}}$ but not Flag-Kr-h1 $1^{\mathrm{S} 154 \mathrm{~A}}$ was recognized by the anti-phospho-Kr-h1 (Ser ${ }^{154}$ ) antibody. Knowing that p$\mathrm{Kr}-\mathrm{h} 1 \mathrm{had}$ an essential role in suppressing E93 reporter activity, we next performed in vivo ChIP analysis using anti-phospho-Kr-h1 (Ser ${ }^{154}$ ) antibody and nuclear extracts from mid-4th and 5th instar nymphs. The antibodies against $\mathrm{Kr}-\mathrm{h} 1$ and IgG were used as the positive and negative controls, respectively. As shown in Fig. 3C, p-Kr-h1 was remarkably enriched with $E 93$ promoter region covering the KBS motif in penultimate 4th instar nymphs in which $\mathrm{JH}, \mathrm{Kr}-\mathrm{h} 1$, and $\mathrm{p}-\mathrm{Kr}-\mathrm{h} 1$ were in high levels. Conversely, a marginal precipitation of $\mathrm{p}-\mathrm{Kr}-\mathrm{h} 1$ was observed at final 5th nymphal instar when $\mathrm{JH}, \mathrm{Kr}$ h1, and p-Kr-h1 levels were low (Fig. 3C). NPC15437

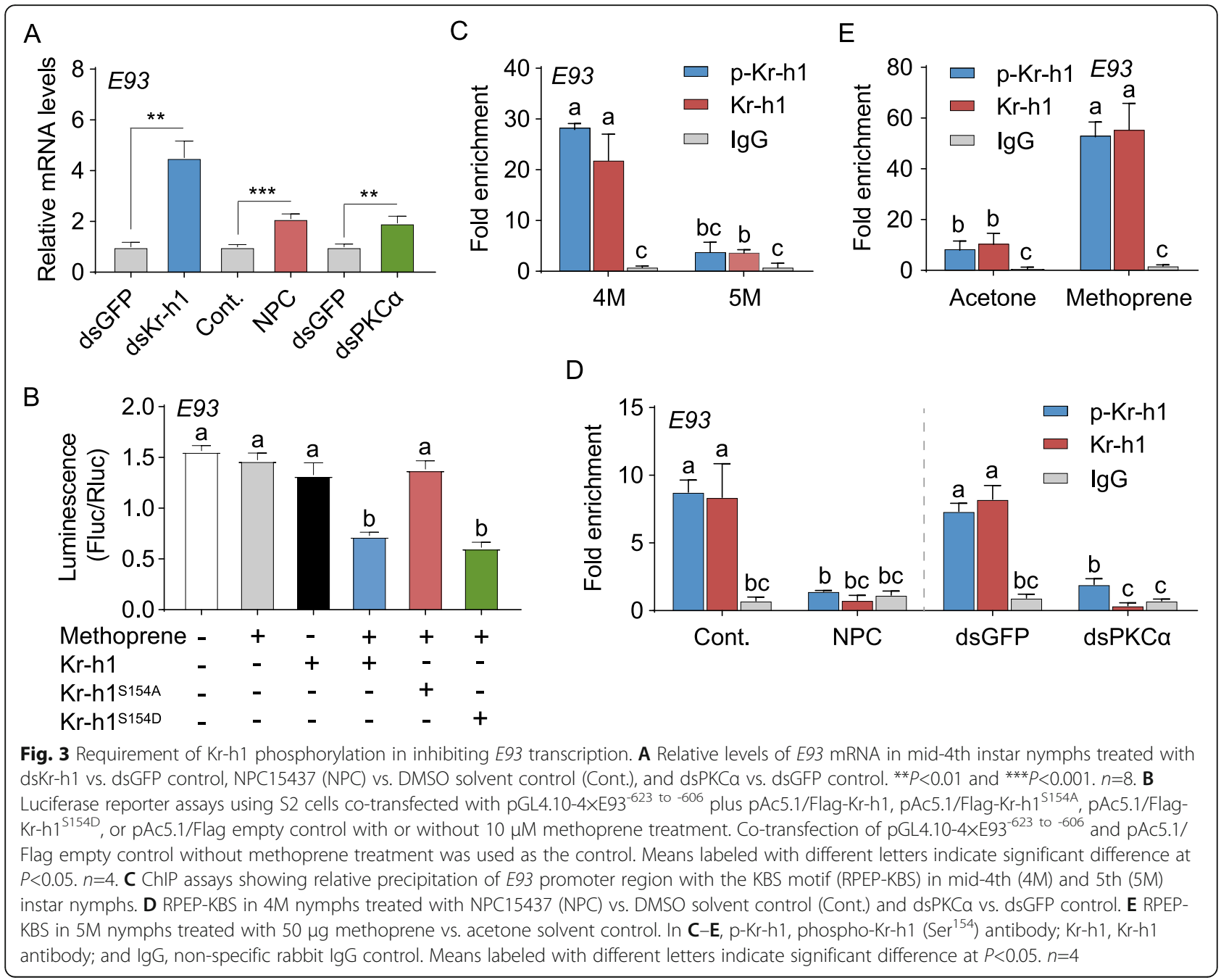


treatment or $P K C \alpha$ knockdown restrained $\mathrm{p}-\mathrm{Kr}-\mathrm{h} 1$ enrichment with KBS-containing E93 promoter region in 4th instar nymphs (Fig. 3D). Moreover, methoprene treatment of 5th instar nymphs caused noticeable increase of p-Kr-h1 enrichment (Fig. 3E). Collectively, these results suggest an essential role of $\mathrm{Kr}-\mathrm{h} 1$ phosphorylation in transcriptional repression of $E 93$ in the nymphs of $L$. migratoria.

\section{$\mathrm{Kr}-\mathrm{h} 1$ phosphorylation is required for its role in stimulating reproduction}

$\mathrm{Kr}-\mathrm{h} 1$ has a dual role in preventing precocious nymphal/ larval metamorphosis and in promoting adult reproduction. In L. migratoria, Ribosomal protein L36 (RL36) (GenBank: MT081313) was previously found to express in response to the JH-Met-Kr-h1 pathway [52]. RL36 is a component of the $60 \mathrm{~S}$ subunit of ribosomes involved in ribosome biogenesis and protein translation as well as extra-ribosomal functions in various cellular processes [53]. Knocking down RL36 resulted in blocked ovarian growth and arrested oocyte maturation
(Additional file 1: Fig. S6). As shown in Fig. 4A, $K r-h 1$ knockdown caused 54\% reduction of RL36 mRNA levels. Similarly, NPC15437 treatment and $P K C \alpha$ knockdown resulted in $41 \%$ and $58 \%$ decrease of RL36 transcripts, respectively (Fig. 4A), suggesting a possible role of $\mathrm{p}-\mathrm{Kr}$ h1 in RL36 expression. For luciferase reporter assay, $R L 36$ promoter region (nt -1647 to -1632 ) comprising a KBS motif (Additional file 1: Fig. S5A) was cloned into pGL4.10 vector. Co-transfection of pAc5.1/Flag-Kr-h1 and pGL4.10-4×RL36 ${ }^{-1647 \text { to }-1632}$ in S2 cells treated with methoprene brought about 2-fold induction of RL36 reporter activity compared to the empty vector control (Fig. 4B). When pAc5.1/Flag-Kr-h1 $1^{\mathrm{S} 154 \mathrm{~A}}$ was cotransfected with pGL4.10-4×RL36 $6^{-1647}$ to -1632 , no significant induction of $R L 36$ reporter activity was observed (Fig. 4B). However, the induction of $R L 36$ reporter activity was restored by overexpression of Flag- $\mathrm{Kr}-\mathrm{h} 1^{\mathrm{S} 154 \mathrm{D}}$ (Fig. 4B). The data indicate an essential role of $\mathrm{Kr}-\mathrm{h} 1$ phosphorylation in RL36 transcription. We next performed ChIP assays to quantify in vivo binding of $\mathrm{p}-\mathrm{Kr}$ h1 to KBS-containing promoter region of $R L 36$ in the fat

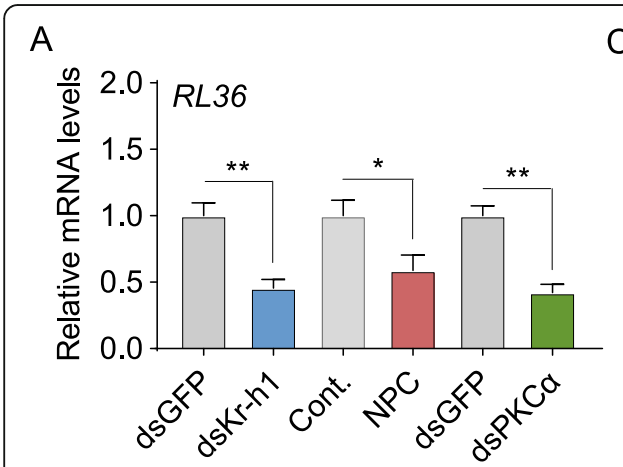

B

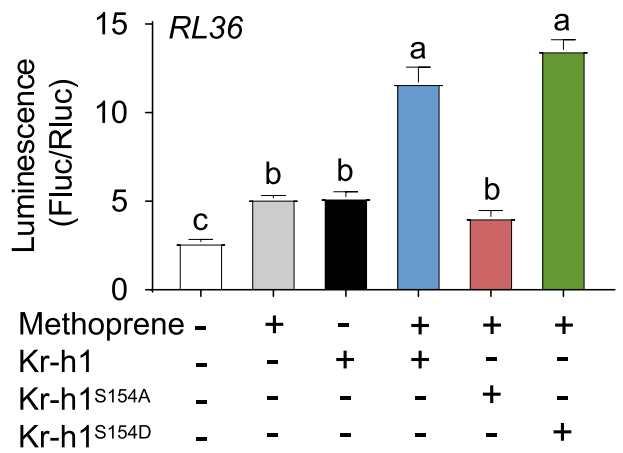

E
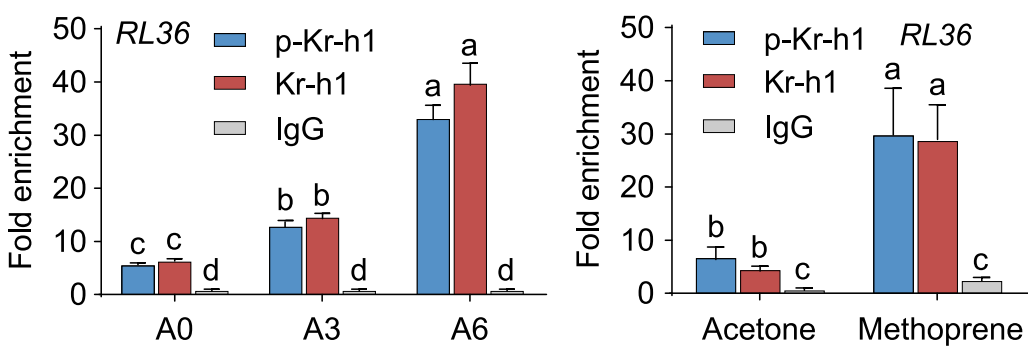

Fig. 4 Requirement of $\mathrm{Kr}-\mathrm{h} 1$ phosphorylation in induction of $R L 36$ transcription. A Relative levels of $R L 36$ transcript in the fat body of 3 -day-old adult females treated with dsKr-h1 vs. dsGFP control, NPC15437 (NPC) vs. DMSO solvent control (Cont.), and dsPKCa vs. dsGFP control. *P<0.05 and ${ }^{* *} P<0.01$. $n=8$. B Luciferase reporter assays using S2 cells co-transfected with pGL4.10-4×RL36 ${ }^{-1647 \text { to }-1632}$ plus pAc5.1/Flag-Kr-h1, pAc5.1/Flag$\mathrm{Kr}-\mathrm{h} 1^{\mathrm{S154A}}$, pAc5.1/Flag-Kr-h1 ${ }^{\mathrm{S154D}}$, or pAc5.1/Flag empty control. Methoprene was applied at $10 \mu \mathrm{M}$. Co-transfection of pGL4.10-4×RL36 ${ }^{-1647}$ to -1632 and pAc5.1/Flag empty vector without methoprene treatment was used as the control. Means labeled with different letters indicate significant difference at $P<0.05 . n=4$. C ChIP assays showing relative precipitation of $R L 36$ promoter region with the KBS motif (RPRP-KBS) in the fat body of adult females on day 0 (A0), day 3 (A3), and day 6 (A6). D RPRP-KBS in the fat body of 3-day-old adult females treated with NPC15437 (NPC) vs. DMSO solvent control (Cont.) and dsPKCa vs. dsGFP control. E RPRP-KBS in the fat body of 3-day-old adult females treated with $50 \mu \mathrm{g}$ methoprene vs. acetone solvent control. In C-E, p-Kr-h1, phospho-Kr-h1 (Ser ${ }^{154}$ ) antibody; Kr-h1, Kr-h1 antibody; and IgG, non-specific rabbit IgG control. Means labeled with different letters indicate significant difference at $P<0.05 . n=4$ 
body of adult females. Compared to the day of adult emergence, $\mathrm{p}-\mathrm{Kr}-\mathrm{h} 1$ was more enriched with the KBScontaining promoter sequence of $R L 36$ on day 3 , and even more on day 6 (Fig. 4C). However, NPC15437 treatment and $P K C \alpha$ knockdown in 6-day-old adult females resulted in significant reduction of $\mathrm{p}-\mathrm{Kr}-\mathrm{h} 1$ enrichment with RL36 promoter (Fig. 4D). Furthermore, application of methoprene to newly emerged adult females led to significantly enhanced precipitation of $\mathrm{p}$ $\mathrm{Kr}$-h1 in RL36 promoter region (Fig. 4E). These results together indicate a pivotal role of $\mathrm{Kr}$-h1 phosphorylation in induction of $R L 36$ transcription during female reproduction.

\section{Phosphorylated Kr-h1 recruits distinct cofactors in anti- metamorphic and vitellogenic actions}

$\mathrm{Kr}-\mathrm{h} 1$ is known to act as a repressor and an activator in transcriptional response to $\mathrm{JH}[8,11,26,27]$. We performed ChIP analysis using the $\mathrm{Kr}-\mathrm{h} 1$ antibody followed by LC-MS/MS as well as yeast two-hybrid assay to identify the co-factors of $\mathrm{Kr}$-h1 in repressing nymphal metamorphosis and promoting adult reproduction. C-terminal binding protein $(\mathrm{CtBP})$ is a highly conserved transcriptional corepressor involved in insect development and reproduction [54-56]. In L. migratoria, CtBP (GenBank: MT081314) expression was high in nymphs, but significantly decreased in adults (Additional file 1: Fig. S7A). Knockdown of $C t B P$ caused significantly increased levels of E93 transcript in penultimate 4th instar nymphs (Additional file 1: Fig. S7B), suggesting a crucial role of CtBP in repressing $E 93$ expression. To assess the $\mathrm{p}-\mathrm{Kr}-\mathrm{h} 1$ and CtBP interaction as well as the effect on E93 transcription, Co-IP and luciferase reporter assays were performed using S2 cells co-transfected with recombinant pAc5.1/Flag-CtBP along with pAc5.1/Flag-Krh1, pAc5.1/Flag-Kr-h1 ${ }^{\text {S154A }}$, or pAc5.1/Flag-Kr-h1 ${ }^{\text {S154D }}$

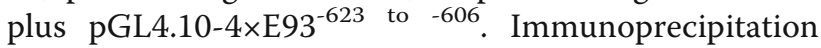
with anti-Kr-h1 antibody followed by western blot with anti-Flag antibody demonstrated that methoprene-exposed Flag-Kr-h1 and Flag-Kr-h1 ${ }^{\text {S154D }}$ but not Flag-Kr-h1 $1^{\text {S154A }}$ interacted with Flag-CtBP (Fig. 5A). Dual luciferase reporter assays showed that E93 reporter activity was reduced by $47 \%$ and $50 \%$, respectively when Flag-CtBP was co-expressed with Flag-Kr-h1 or Flag-Kr-h1 $1^{\text {S154D }}$ (Fig. 5B). In contrast, co-expression of Flag-CtBP and Flag-Kr-h1 ${ }^{\mathrm{S} 154 \mathrm{~A}}$ had no significant inhibitory effect on E93 reporter activity (Fig. 5B). The data suggest that phosphorylated $\mathrm{Kr}-\mathrm{h} 1$ recruits a repressor, CtBP in transcriptional repression of $E 93$ gene for anti-metamorphic action in nymphal locusts.

CREB-binding protein (CBP), a transcriptional coactivator with histone acetyltransferase activity, has been demonstrated to play an important role in $\mathrm{JH}$ action [34, 57, 58]. In L. migratoria, CBP (GenBank: MT081315) mRNA levels significantly increased after adult ecdysis (Additional file 1: Fig. S7C). Depletion of CBP caused $49 \%$ reduction of RL36 mRNA levels in the fat body of 3-day-old adult females (Additional file 1: Fig. S7D), suggesting that $\mathrm{CBP}$ is likely to participate in $\mathrm{Kr}-\mathrm{h} 1$ regulation of RL36 transcription. Co-IP assays showed that Flag-CBP dimerized with methoprene-treated $\mathrm{Kr}-\mathrm{h} 1$ and $\mathrm{Kr}-\mathrm{h} 1^{\text {S154D }}$, but not Kr-h1 ${ }^{\text {S154A }}$ (Fig. 5C). In dual luciferase reporter assays, co-transfection of pAc5.1/Flag-CBP and pAc5.1/Flag-Kr-h1 ${ }^{\text {S154D }}$ caused 1.7-fold increase of $R L 36$ reporter activity, mimicking that observed with coexpression of Flag-CBP and Flag-Kr-h1 (Fig. 5D). Conversely, no significantly enhanced $R L 36$ reporter activity was observed with co-expression of Flag-CBP and Flag$\mathrm{Kr}-\mathrm{h} 1^{\mathrm{S} 154 \mathrm{~A}}$ (Fig. 5D). Taken together, these results imply that phosphorylated $\mathrm{Kr}$-h1 recruits a coactivator, CBP for induction of $R L 36$ transcription that is involved in locust vitellogenesis and egg maturation.

\section{$\mathrm{Kr}-\mathrm{h} 1$ phosphorylation is evolutionarily conserved}

We next investigated the evolutionary conservation of $\mathrm{Kr}-\mathrm{h} 1$ phosphorylation across insect orders. Protein sequence alignment indicated that this phosphorylation residue is conserved in $\mathrm{Kr}$-h1 orthologues of other 22 insect species with available cDNA sequences in the NCBI database (Additional file 1: Fig. S8A). We selected the $\mathrm{Kr}$-h1 orthologues of holometabolous species B. mori, T. castaneum, and D. melanogaster for further study. Ser ${ }^{154}$ of L. migratoria $\mathrm{Kr}-\mathrm{h} 1$ is homologous to $\mathrm{Ser}^{76}$ of $B$. mori Kr-h1 (BmKr-h1), Ser ${ }^{124}$ of T. castaneum Kr-h1 (TcKrh1), and $\operatorname{Ser}^{255}$ of D. melanogaster Kr-h1 (DmKr-h1). Amino acids at the flanking regions of these serine residues occur in a highly conserved context (Additional file 1: Fig. S8A). The phosphorylated forms of $\mathrm{Kr}-\mathrm{h} 1$ orthologues in B. mori, T. castaneum and D. melanogaster were recognized by anti-phospho-Kr-h1 (Ser $\left.{ }^{154}\right)$ antibody (Fig. 6A). The results indicate the conservation of $\mathrm{Kr}-\mathrm{h} 1$ phosphorylation across insect orders, including hemimetabolous and holometabolous species. The regulatory sequences containing the core KBS motif were previously identified in the promoters of B. mori, T. castaneum, and D. melanogaster E93 corresponding genes [17] (Additional file 1: Fig. S8B). Thus, we performed dual luciferase reporter assays to characterize the inhibitory effect of BmKr-h1, TcKr-h1, and DmKr-h1 phosphorylation on transcription of respective E93 genes. Compared to the empty vector control, overexpression of methoprene-treated BmKr-h1 and BmKr-h1 ${ }^{\mathrm{S} 76 \mathrm{D}}$ led to $67 \%$ and $73 \%$ reduction of $B m E 93$ reporter activity, whereas overexpression of $\mathrm{BmKr}-\mathrm{h} 1^{\mathrm{S} 76 \mathrm{~A}}$ had no inhibitory effect (Fig. 6B). With respect to TcKr-h1 phosphorylation, methoprene-exposed TcKr-h1 and TcKr-h1 $1^{\text {S124D }}$ 


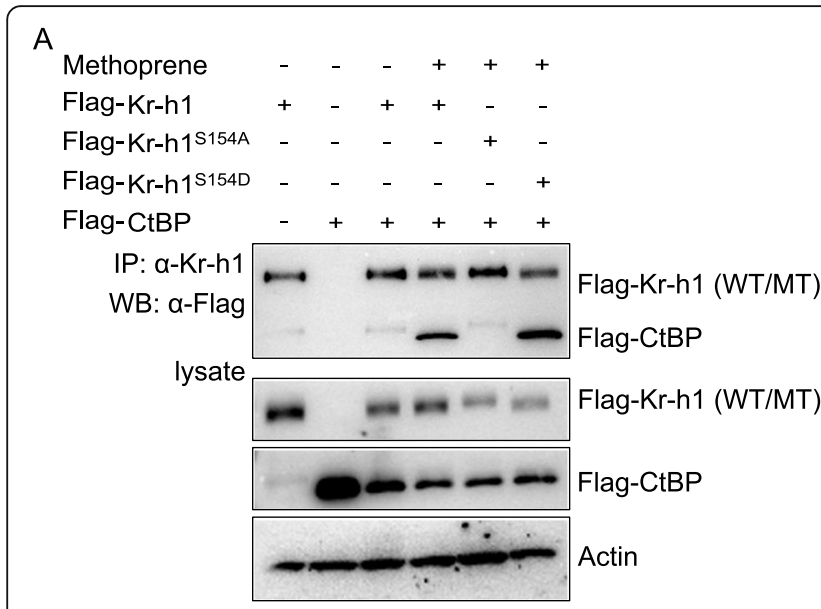

B

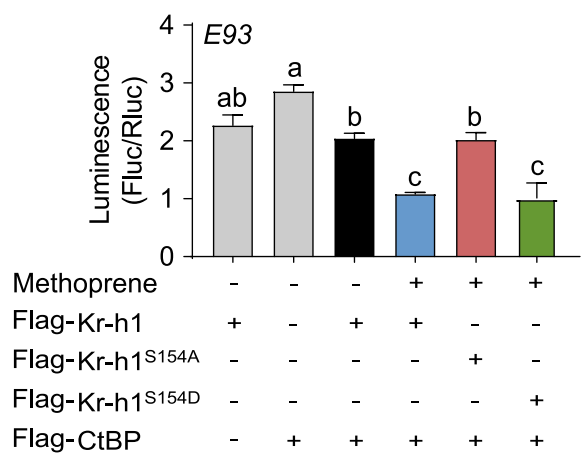

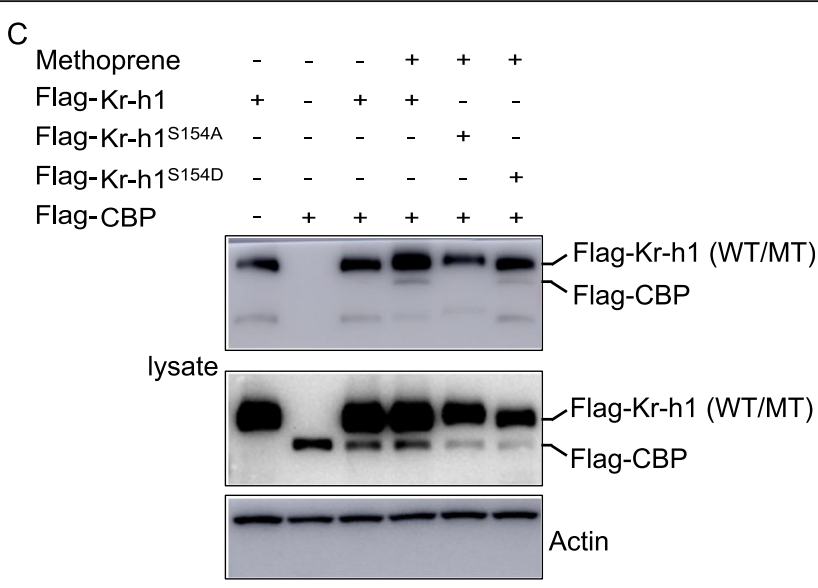

D

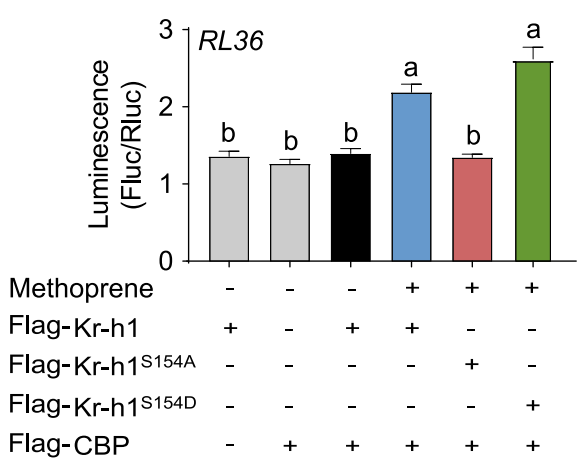

Fig. 5 Essential role of Kr-h1 phosphorylation in the interaction with transcriptional cofactors. A Upper panel: immunoprecipitation (IP) and western blot (WB) showing the interaction of Flag-Kr-h1, Flag-Kr-h1 ${ }^{\mathrm{S} 154 \mathrm{~A}}$, or Flag-Kr-h1 ${ }^{\mathrm{S} 154 \mathrm{D}}$ with Flag-CtBP. Middle and lower panels: the expression of above recombinant proteins in S2 cells. a-Kr-h1, Kr-h1 antibody; a-Flag, Flag antibody. WT, wildtype; MT, mutant. B Luciferase reporter assays after co-transfection of pGL4.10-4XE93-623 to -606 and pAc5.1/Flag-CtBP plus pAc5.1/Flag-Kr-h1, pAc5.1/Flag-Kr-h1 ${ }^{\text {S14A }}$, or pAc5.1/ Flag-Kr-h1 ${ }^{\text {S154D }}$ into S2 cells. Co-transfection of pGL4.10-4XE93-623 to -606 and pAc5.1/Flag-Kr-h1 was used as the control. Methoprene was applied at $10 \mu \mathrm{M}$. Means labeled with different letters indicate significant difference at $P<0.05$. $n=4$. C Upper panel: IP and WB showing interaction of Flag-Kr-h1, Flag-Kr-h1 ${ }^{\text {S154A }}$ or Flag-Kr-h1 ${ }^{\text {S154D }}$ with Flag-CBP. Mid and lower panels: the expression of above recombinant proteins in S2 cells. a-Krh1, Kr-h1 antibody; a-Flag, Flag antibody. WT, wildtype; MT, mutant. D Luciferase reporter assays after co-transfection of pGL4.10-4XRL36-1647 to

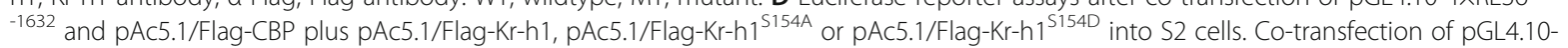
4XRL36 ${ }^{-1647}$ to -1632 and pAc5.1/Flag-Kr-h1 was used as the control. Methoprene was applied at $10 \mu \mathrm{M}$. Means labeled with different letters indicate significant difference at $P<0.05 . n=4$

caused $91 \%$ and $71 \%$ reduction, respectively of TcE93 reporter activity (Fig. 6C). No inhibitory effect of TcKr$\mathrm{h} 1^{\mathrm{S} 124 \mathrm{~A}}$ on TcE93 reporter activity was observed (Fig. 6C). In the case of DmKr-h1 phosphorylation, methoprene-treated DmKr-h1 and DmKr-h1 ${ }^{\text {S255D }}$ brought about $85 \%$ and $81 \%$ reduction, respectively, of DmE93 reporter activity (Fig. 6D). Overexpression of DmKr-h1 ${ }^{\text {S255A }}$ led to $44 \%$ reduction of DmE93 reporter activity. Nevertheless, the transcriptional activity of DmKr-h1 ${ }^{\text {S255A }}$ was significantly lower than that of methoprene-exposed DmKr-h1 and DmKr-h1 ${ }^{\text {S255D }}$ (Fig. 6D). Collectively, these results indicate that Kr-h1 phosphorylation and its indispensable role in regulating E93 expression are evolutionarily conserved in B. mori, T. castaneum, and D. melanogaster.

\section{Discussion}

As a primary $\mathrm{JH}$ early-response gene, $K r-h 1$ plays an essential role in mediating $\mathrm{JH}$ action in repressing metamorphosis in juveniles and stimulating reproduction in adults [8-11]. Previous studies have established that $\mathrm{Kr}$ $h 1$ is transcriptionally activated by the JH-receptor complex [15, 29-31]. In addition, $K r-h 1$ is reported to be post-transcriptionally regulated by miRNAs, including miR-2, let-7, and miR-278, in different species [37, 38]. Furthermore, $K r-h 1$ transcription is regulated by HDAC1-mediated histone deacetylation, suggesting an epigenetic modification in $\mathrm{JH}$ action $[34,35]$. Thus, $\mathrm{Kr}$ h1 phosphorylation represents an interesting question for comprehensively deciphering the molecular basis of $\mathrm{JH}$ action and $\mathrm{Kr}-\mathrm{h} 1$ function. By approaches of site- 

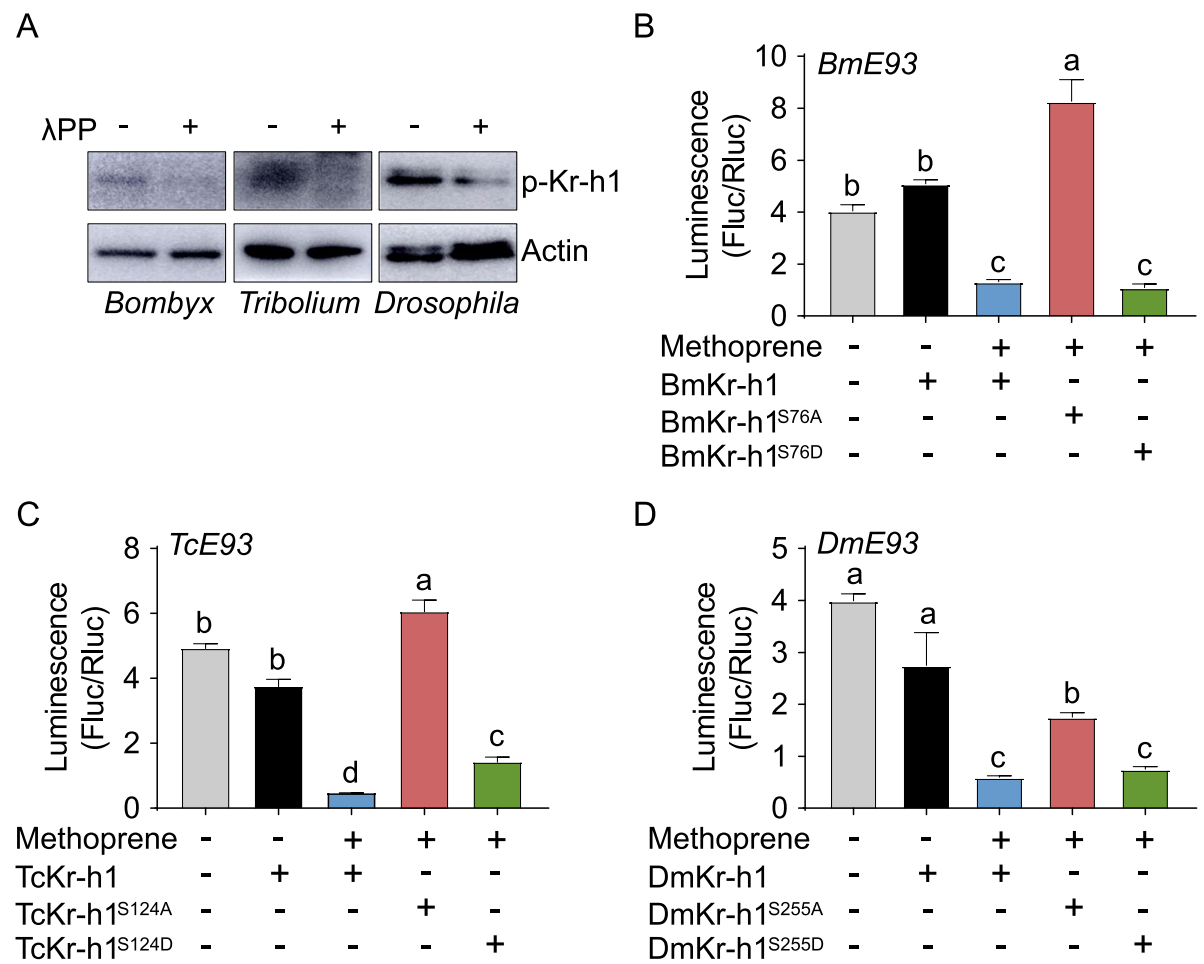

Fig. 6 Conservation of Kr-h1 phosphorylation in other insects. A Western blot showing Kr-h1 phosphorylation in penultimate instar larvae of Bombyx mori, Tribolium castaneum, and Drosophila melanogaster, respectively. B Luciferase reporter assays after co-transfection of pGL4.104XBmE93 ${ }^{-2844}$ to -2827 with pAc5.1/Flag-BmKr-h1, pAc5.1/Flag-BmKr-h1 ${ }^{\text {S76A }}$, pAc5.1/Flag-BmKr-h1 ${ }^{\text {S76D }}$ or pAc5.1/Flag vector control into S2 cells. Methoprene was applied at $10 \mu \mathrm{M}$. C Luciferase reporter assays using S2 cells co-transfected with pGL4.10-4XTcE93 ${ }^{-50}$ to -33 with pAc5.1/FlagTcKr-h1, pAc5.1/Flag-TcKr-h1 1 $124 \mathrm{~A}$, pAc5.1/Flag-TcKr-h1 ${ }^{\mathrm{S124D}}$, or pAc5.1/Flag. D Luciferase reporter assays using S2 cells co-transfected with pGL4.10-4×DmE93-2095 to -2078 with pAc5.1/Flag-DmKr-h1, pAc5.1/Flag-DmKr-h1 ${ }^{\text {S255A }}$, pAc5.1/Flag-DmKr-h1 ${ }^{\text {S255D }}$ or pAc5.1/Flag. Means labeled with different letters indicate significant difference at $P<0.05 . n=3$

directed mutagenesis, phosphoprotein gel staining, LCMS/MS, RNAi, western blot, and ChIP, we found in this study that $\mathrm{Kr}$-h1 was phosphorylated by $\mathrm{PKC} \alpha$ at $\mathrm{Ser}^{154}$ and that $\mathrm{Kr}-\mathrm{h} 1$ phosphorylation levels increased along with $\mathrm{JH}$-induced $\mathrm{Kr}$-h1 expression. We observed more rapid increase of $\mathrm{Kr}-\mathrm{h} 1$ phosphorylation than total $\mathrm{Kr}-\mathrm{h} 1$ protein after 15-min exposure to methoprene in locusts. $\mathrm{JH}$-induced phosphorylation was also seen with the recombinant Flag-Kr-h1 protein expressed in S2 cells. It has been previously reported that $\mathrm{JH}$ promotes Met phosphorylation by CaMKII and PKC and thus enhances the transcriptional activity of Met in Ae. aegypti [41, 43]. Moreover, JH triggers Akt-mediated serine/arginine-rich (pre-mRNA) splicing factor (SRSF) phosphorylation that induces Taiman alternative splicing and promotes $A e$. aegypti vitellogenesis [40]. Additionally, it has been shown that $\mathrm{JH}$ induces Met phosphorylation and consequently increases the dimerization of Met and Tai in $H$. armigera [59]. Recently, a functional phosphorylation site $\left(\mathrm{Ser}^{694}\right)$ located outside of multiple zinc-finger domains was identified in Ae. aegypti Kr-h1 (AaKr-h1). JH treatment caused dephosphorylation of AaKr-h1 at $\mathrm{Ser}^{694}$. Dephosphorylation mimic mutants $\left(\mathrm{AaKr}-\mathrm{h} 1^{\mathrm{S} 694 \mathrm{~V}}\right.$ and $\mathrm{AaKr}-\mathrm{h} 1^{\mathrm{S} 694 \mathrm{C}}$ ) showed significantly higher transcriptional activity than wildtype AaKr-h1 [60]. Our present study provides evidence on $\mathrm{Kr}-\mathrm{h} 1$ phosphorylation at a serine residue in the zinc-finger domains and extends the view of post-translational modification of key players in the $\mathrm{JH}$ pathway. In a previous report, we demonstrated that JH activates the GPCR/RTK-PLC-IP3R signaling pathway that triggers PKC-mediated phosphorylation of $\mathrm{Na}^{+} / \mathrm{K}^{+}$-ATPase involved in patency induction and $\mathrm{Vg}$ transportation in vitellogenic female locusts [39]. We speculate that JH-activated GPCR/ RTK-PLC-IP3R signaling cascade might induce PKC $\alpha$ triggered $\mathrm{Kr}-\mathrm{h} 1$ phosphorylation.

$\mathrm{Kr}-\mathrm{h} 1$ is capable of activating or repressing transcription of genes in response to $\mathrm{JH}$ bound to its receptor Met $[8,11,26,27]$. Our cell culture-based luciferase reporter assay and in vivo ChIP analysis demonstrated that $\mathrm{Kr}$-h1 phosphorylation at $\mathrm{Ser}^{154}$ is essential for the transcriptional regulation of $E 93$ and $R L 36$, two representatives of $\mathrm{Kr}$-h1 target genes. Such a phosphorylation was required for $\mathrm{Kr}-\mathrm{h} 1$ to interact with the corepressor $\mathrm{CtBP}$ in inhibiting $E 93$ transcription and with the coactivator CBP in inducing RL36 transcription. The $\mathrm{p}-\mathrm{Kr}-\mathrm{h} 1$ 
wildtype variant Flag-Kr-h1 ${ }^{\mathrm{S} 154 \mathrm{D}}$ had similar capability to $\mathrm{p}-\mathrm{Kr}-\mathrm{h} 1$ in binding cofactors and exerting transcriptional activity. However, the $\mathrm{Kr}-\mathrm{h} 1^{\mathrm{S} 154 \mathrm{~A}}$ mutant was unable to recruit the cofactors, consequently abolishing the repression of E93 transcription and the induction of RL36 transcription. These results together address the importance of $\mathrm{Kr}-\mathrm{h} 1$ phosphorylation in mediating antimetamorphic and vitellogenic effects of $\mathrm{JH}$.

The $\mathrm{Kr}$-h1 sequence contains eight $\mathrm{C}_{2} \mathrm{H}_{2}$ zinc-finger domains. In addition to potentially recognizing a variety of DNA sequences, the zinc-fingers act as a hub for protein-protein interaction [61, 62]. The $\operatorname{Ser}^{154}$ residue is localized at the 3rd zinc-finger domain of $\mathrm{Kr}-\mathrm{h} 1$. Phosphorylation modification is likely to induce a conformational change that is optimal for $\mathrm{Kr}$-h1 to recruit cofactors. In the present study, CtBP and CBP were found to bind with phosphorylated $\mathrm{Kr}-\mathrm{h} 1$ in repressing E93 transcription and activating RL36 transcription, respectively. Nevertheless, phosphorylated Kr-h1 could also interact with other cofactors in transcriptional activation or repression of target genes. In Ae. aegypti, $\mathrm{Kr}$ h1 acts synergistically with Hairy, thereby mediating the action of Met in gene repression during previtellogenic development of adult females [27, 63]. A study in $N$. lugens has demonstrated that Hairy directly interacts with the $\mathrm{N}$-terminus zinc-finger domains of $\mathrm{Kr}$-h1 in modulating gene transcription [64]. Dual functions of transcriptional activation and repression are widely observed with transcription factors [65-70]. In mammals, Krüppel-like factor 4 promotes the transcription of $c y c$ lin B1 via interacting with CBP, but downregulates cyclin $B 1$ transcription by recruiting HDAC3 [66].

We have additionally shown $\mathrm{Kr}$-h1 phosphorylation in other insects belonging to divergent orders, including the lepidopteran $B$. mori, the coleopteran $T$. castaneum, and the dipteran $D$. melanogaster. The requirement of phosphorylation for $\mathrm{Kr}-\mathrm{h} 1$ action on suppressing E93 transcription was found to be also conserved. The findings provide a clear indication that $\mathrm{Kr}$-h1 phosphorylation and its indispensable role in regulating target gene expression are evolutionarily conserved across distant insect orders. These observations further highlight the significance of $\mathrm{Kr}-\mathrm{h} 1$ phosphorylation in eliciting transcriptional activity. Previously, $\mathrm{JH}$-dependent $A e$. aegypti $\mathrm{Kr}$-h1 dephosphorylation at $\mathrm{Ser}^{694}$ has been demonstrated to enhance the transcriptional activity [60]. The phosphoserine residue $\operatorname{Ser}^{694}$ is conserved in some holometabolous insects but not in L. migratoria. The Ser ${ }^{154}$ of L. migratoria $\mathrm{Kr}-\mathrm{h} 1$ is homologous to $\mathrm{Ser}^{206}$ of Ae. aegypti Kr-h1. Thus, Kr-h1 orthologues likely bear multiple phosphorylation sites with differential responses to $\mathrm{JH}$. While evolutionarily conserved $\mathrm{Kr}$-h1 phosphorylation sites occur in divergent insect species, the lineage- and species-specific $\mathrm{Kr}-\mathrm{h} 1$ phosphorylation residues may exist in some insects. It is of interest to address these questions in future research.

\section{Conclusions}

$\mathrm{Kr}$-h1 functions both as a transcriptional repressor in preventing precocious larval/nymphal metamorphosis and a transcriptional activator in stimulating adult reproduction in insects. $\mathrm{PKC} \alpha$ phosphorylated $\mathrm{Kr}-\mathrm{h} 1$ at a serine residue localized in the $3^{\text {rd }}$ zinc-finger domain. While Kr-h1 phosphorylation levels increased along with $\mathrm{JH}$-induced total $\mathrm{Kr}$-h1 expression, more rapid increase of $\mathrm{Kr}$-h1 phosphorylation than total $\mathrm{Kr}$-h1 was observed in locusts treated with methoprene. JH-induced $\mathrm{Kr}$-h1 phosphorylation was also seen in methoprene-exposed S2 cells. Phosphorylated $\mathrm{Kr}-\mathrm{h} 1$ recruited CtBP in nymphs, which inhibited E93 expression and metamorphosis. Phosphorylated Kr-h1 recruited CBP in adults, consequently stimulating RL36 transcription and vitellogenesis. Kr-h1 phosphorylation and its essential role in recruiting CtBP and repressing E93 expression are evolutionarily conserved in L. migratoria, B. mori, T. castaneum, and D. melanogaster. Thus, our present study fills a knowledge gap of phosphorylation modification of $\mathrm{Kr}$ h1, an intermediate regulator in the $\mathrm{JH} /$ Met-response gene expression hierarchy.

\section{Methods}

\section{Insects and treatments}

The gregarious phase of L. migratoria was maintained as previously reported [71]. s-(+)-methoprene (Santa Cruz Biotech) was topically applied at $10-100 \mu \mathrm{g} / 5 \mu \mathrm{l}$ acetone per locust for $8 \mathrm{~h}$ or $100 \mu \mathrm{g} / 5 \mu \mathrm{l}$ acetone per locust for 5 60 min. NPC15437 (Abcam) was intra-abdominally injected at $0.25 \mu \mathrm{g} / 5 \mu \mathrm{l} \mathrm{DMSO}$ per locust.

\section{LC-MS/MS analysis}

Synthesized Kr-h1(aa125-159) and Kr-h1 ${ }^{\mathrm{S154A}}$ (aa125-159) peptides (BiotechPark) were separately incubated with $\mathrm{PKC} \alpha$ (SignalChem) in reaction buffer containing $50 \mathrm{mM}$ Tris- $\mathrm{HCl}$ (pH 7.5), $100 \mathrm{mM} \mathrm{NaCl}, 20 \mathrm{mM} \mathrm{MgCl}, 1 \mathrm{mM}$ DTT, and $1 \mathrm{mM} \mathrm{ATP}$ at $30^{\circ} \mathrm{C}$ for $30 \mathrm{~min}$. After termination with $1 / 10$ volume $1 \%$ formaldehyde and centrifugation at $8000 \times g$ for $10 \mathrm{~min}$, the supernatant was desalted by C18Zip-Tip (Millipore), reduced by $10 \mathrm{mM}$ DTT at $56^{\circ} \mathrm{C}$ for $1 \mathrm{~h}$, and alkylated by $20 \mathrm{mM}$ iodoacetamide (IAA) at room temperature in dark for $1 \mathrm{~h}$. Extracted peptides were then lyophilized and resuspended in $0.1 \%$ formic acid, followed by LC-MS/MS analysis.

\section{Pro-Q Diamond Phosphoprotein Gel Stain}

cDNA fragments for $\mathrm{Kr}-\mathrm{h} 1(\mathrm{aa} 1-290), \mathrm{Kr}-\mathrm{h} 1^{\mathrm{S} 154 \mathrm{~A}}$ (aa1290), Kr-h1(aa89-312), Kr-h1 ${ }^{\mathrm{S1} 154 \mathrm{~A}}$ (aa89-312), and $\mathrm{Kr}$ h1(aa291-591) were separately cloned into pGEX-4t-1 vector (GE Healthcare) for overexpression of 
recombinant GST-tagged proteins in Escherichia coli Rosetta competent cells (Transgen). Cells were lysed by sonication in lysis buffer with $50 \mathrm{mM}$ Tris- $\mathrm{HCl} \mathrm{pH} 7.5$ plus $0.1 \%$ Triton $\mathrm{X}-100$ and cleared by centrifugation at $8000 \times g$ for $30 \mathrm{~min}$ at $4^{\circ} \mathrm{C}$. GST-fusion proteins were purified by GST resin (Thermo Fisher Scientific) and incubated with PKC $\alpha$ (SignalChem), followed by SDSPAGE and Pro-Q Diamond Phosphoprotein Gel Stain (Invitrogen).

\section{Eukaryotic cell culture and protein expression}

Protein coding sequences of Kr-h1 (nt 1-1776), CtBP (nt 1-1332), CBP (nt 1-1728), BmKr-h1 (nt 1-1086), TcKrh1 (nt 1-1407), and DmKr-h1 (nt 1-2376) were separately cloned into pAc5.1/Flag vectors (Invitrogen). Sitedirected mutagenesis for $\mathrm{Kr}-\mathrm{h} 1^{\mathrm{S} 154 \mathrm{~A}}, \mathrm{Kr}-\mathrm{h} 1^{\mathrm{S} 154 \mathrm{D}}, \mathrm{BmKr}$ $\mathrm{h} 1^{\mathrm{S} 76 \mathrm{~A}}, \mathrm{BmKr}-\mathrm{h} 1^{\mathrm{S} 76 \mathrm{D}}, \quad \mathrm{TcKr}-\mathrm{h} 1^{\mathrm{S} 124 \mathrm{~A}}, \mathrm{TcKr}-\mathrm{h} 1^{\mathrm{S} 124 \mathrm{D}}$, $\mathrm{DmKr}-\mathrm{h} 1^{\mathrm{S} 255 \mathrm{~A}}$, and $\mathrm{DmKr}-\mathrm{h} 1^{\mathrm{S} 255 \mathrm{D}}$ was performed using Q5 Site-Directed Mutagenesis Kit (NEB). S2 cells were transfected with the recombinant vectors using Lipofectamine 3000 (Thermo). Primers used for recombinant vector construction and site-directed mutagenesis are provided in Table S1 (Additional file 1) and Table S2 (Additional file 1), respectively.

\section{Western blot and immunoprecipitation}

Protein extracts from insects and S2 cells were isolated in ice-cold lysis buffer containing $150 \mathrm{mM} \mathrm{NaCl}, 50 \mathrm{mM}$ Tris- $\mathrm{HCl}$ (pH 7.4), 1 mM EDTA, $1 \%$ Nonidet P-40, $1 \%$ Triton-X 100, 0.5\% sodium deoxycholate, $1 \mathrm{mM}$ PMSF plus protease, and phosphatase inhibitors (Roche). Lysates were cleared by centrifugation, subjected to $8 \%$ SDS-PAGE, and transferred to PVDF membrane (Millipore). Western blots were conducted using antibodies against Kr-h1 [38], phospho-Kr-h1 (Ser ${ }^{154}$ ) (Jingjie PTM-Biolab), VgA [39] and Flag (MBL), corresponding HRP-conjugated secondary antibody (CWBIO), and a Superstar ECL Plus Ready-to-use Kit (BOSTER). $\beta$-actin antibody [39] was used as a reference control. Band intensity was quantified by ImageJ. For immunoprecipitation, precleared lysates were incubated with anti-Kr-h1 antibody for $60 \mathrm{~min}$ at $4^{\circ} \mathrm{C}$. The immunocomplexes were then captured with protein-A agarose (Sigma-Aldrich) at $4^{\circ} \mathrm{C}$ overnight and eluted in Laemmli sample buffer, followed by western blots with anti-phospho-(Ser) (Blue Light Biotech) or anti-Flag antibody. For phosphatase treatment, protein extracts were preincubated with $\lambda p p$ (New England Biolabs) for $1 \mathrm{~h}$ at $30^{\circ} \mathrm{C}$.

\section{RNA isolation and qRT-PCR}

Total RNAs were extracted from insects and S2 cells using TRIzol reagent (Invitrogen), and first-strand cDNAs were reverse transcribed using FastQuant RT kit with gDNase (Tiangen). qRT-PCR was performed using a RealMasterMix SYBR Green kit (Tiangen) with a LightCycler 96 system (Roche), initiated at $95^{\circ} \mathrm{C}$ for 15 $\mathrm{min}$, and followed by 40 cycles of $95^{\circ} \mathrm{C}$ for $10 \mathrm{~s}, 58^{\circ} \mathrm{C}$ for $20 \mathrm{~s}$, and $72^{\circ} \mathrm{C}$ for $30 \mathrm{~s}$. Relative expression levels were calculated using $2^{-\Delta \Delta C t}$ method, normalized by ribosomal protein 49 (Rp49). Primers for qRT-PCR are listed in Table S3 (Additional file 1).

\section{RNA interference and tissue imaging}

cDNA templates were amplified by PCR, cloned into pGEM-T vector (Tiangen), and confirmed by sequencing. dsRNAs were synthesized by in vitro transcription with T7 RiboMAX Express RNAi System (Promega). Locusts were intra-abdominally injected with $15 \mu \mathrm{g}$ dsRNA, and boosted once on day 5 . Phenotypes were photographed by Canon EOS550D camera and Leica M205C stereomicroscope. Primers used for RNAi are given in Table S3 (Additional file 1).

\section{Dual luciferase reporter assay}

E93 and RL36 promoter regions bearing the KBS motif including $4 \times \mathrm{E} 93^{-623}$ to $-606,4 \times \mathrm{RL}_{3} 6^{-1647}$ to -1632 , $4 \times \mathrm{BmE} 3^{-2844}$ to $-2827,4 \times \mathrm{TcE}^{-25} 3^{-50}$ to ${ }^{-33}$, and $4 \times \mathrm{DmE} 93^{-2095}$ to -2078 were separately ligated into pGL4.10 vector (Promega) and confirmed by sequencing. S2 cells were co-transfected with these constructs along with recombinant vectors expressing wildtype or mutated Kr-h1 of L. migratoria, B. mori, T. castaneum, and D. melanogaster. Methoprene was applied at $10 \mu \mathrm{M} 48 \mathrm{~h}$ post transfection and for $6 \mathrm{~h}$. The luciferase activity was measured using a Dual-Luciferase Reporter Assay System and a GloMAX 96 Microplate Luminometer (Promega).

\section{Chromatin immunoprecipitation}

ChIP assays were performed using an EZ-Magna ChIP A/G Kit (Millipore). Briefly, fat bodies collected from nymph and adult females were fixed with $1 \%$ formaldehyde to crosslink chromatin for $10 \mathrm{~min}$ at $37^{\circ} \mathrm{C}$. After addition of $125 \mathrm{mM}$ glycine, chromatin was sonicated to shear into 200-1000 bp DNA fragments. The complexes were then immunoprecipitated with antibody against $\mathrm{Kr}-\mathrm{h} 1$, phospho-Kr-h1 (Ser ${ }^{154}$ ) or IgG, followed by qPCR. Primers used for ChIP are listed in Table S3 (Additional file 1).

\section{Statistical analysis}

Statistical analyses were performed by Student's $t$-test or one-way analysis of variance (ANOVA) with Tukey's post hoc test using the SPSS22.0 software. Significant difference was considered at $P<0.05$. Values were reported as mean \pm S.E. 


\section{Supplementary Information}

The online version contains supplementary material available at https:/doi. org/10.1186/s12915-021-01157-3.

Additional file 1: Figure S1. Identification of $\mathrm{Kr}-\mathrm{h} 1$ phosphorylation site. Figure S2. Identification of kinase triggering Kr-h1 phosphorylation. Figure S3. Effect of 15-min exposure of methoprene on Kr-h1 phosphorylation. Figure S4. Effect of E93 knockdown on locust metamorphosis. Figure S5. Responsiveness of $\mathrm{Kr}-\mathrm{h} 1$ phosphorylation to JH. Figure S6. Effect of $R L 36$ knockdown on locust reproduction. Figure S7. Effect of $C t B P$ or CBP knockdown on E93 or RL36 expression. Figure S8. Alignment of the $3^{\text {rd }}$ zinc-finger domain of $\mathrm{Kr}$-h1 and the partial promoter sequences of E93 with KBS motifs. Table S1. Primers used for cloning and gene expression. Table S2. Primers used for site-directed mutagenesis. Table S3. Primers used for qRT-PCR, RNAi and ChIP.

Additional file 2. The individual data values for Fig. 3B-E, Fig. 4B-E, Fig. 5B, D, Fig. 6B-D, Fig. S2A and Fig. S3.

Additional file 3. Original Western blot data

\section{Acknowledgements}

We thank Drs. Lynn Riddiford and Marek Jindra for critical reading of this manuscript.

\section{Authors' contributions}

Z.W. and S.Z. designed the research; Z.W., L.Y., and H.L. performed the research; Z.W. and S.Z. analyzed the data; and S.Z. and Z.W. wrote the paper. All authors read and approved the final manuscript.

\section{Funding}

This work was supported by the National Natural Science Foundation of China (NSFC) Grants 31630070 and 31702062.

\section{Availability of data and materials}

All data generated or analyzed during this study are included in this published article and its supplementary information files. The datasets used and/or analyzed during the current study available from the corresponding author on reasonable request.

\section{Declarations}

Ethics approval and consent to participate

Not applicable.

\section{Consent for publication}

Not applicable.

\section{Competing interests}

The authors declare no competing interests.

Received: 7 June 2021 Accepted: 24 September 2021

Published online: 08 October 2021

\section{References}

1. Riddiford LM. Cellular and molecular actions of juvenile hormone I. General considerations and premetamorphic actions. Adv In Insect Phys. 1994;24 213-74. https://doi.org/10.1016/S0065-2806(08)60084-3.

2. Truman JW, Riddiford LM. The evolution of insect metamorphosis: a developmental and endocrine view. Philos Trans R Soc Lond B Biol Sci. 2019;374(1783):20190070. https://doi.org/10.1098/rstb.2019.0070.

3. Belles $X$. The innovation of the final moult and the origin of insect metamorphosis. Philos Trans R Soc Lond B Biol Sci. 2019;374(1783): 20180415. https://doi.org/10.1098/rstb.2018.0415

4. Jindra M. Where did the pupa come from? The timing of juvenile hormone signalling supports homology between stages of hemimetabolous and holometabolous insects. Philos Trans R Soc Lond B Biol Sci. 2019;374(1783): 20190064. https://doi.org/10.1098/rstb.2019.0064.

5. Belles X. Insect metamorphosis. From natural history to regulation of development and evolution. London: Academic Press; 2020.
6. Wyatt GR, Davey KG. Cellular and molecular actions of juvenile hormone II. Roles of juvenile hormone in adult insects. Adv In Insect Phys. 1996;26:1155. https://doi.org/10.1016/S0065-2806(08)60030-2.

7. Raikhel AS, Brown MR, Belles X. Hormonal control of reproductive processes. In: Gilbert LI, latrou K, Gill SS, editors. Comprehensive molecular insect science, vol. 3. Boston: Elsevier; 2005. p. 433-91. https://doi.org/10.1016/ B0-44-451924-6/00040-5

8. Belles X. Krüppel homolog 1 and E93: The doorkeeper and the key to insect metamorphosis. Arch Insect Biochem Physiol. 2020;103(3):e21609. https:// doi.org/10.1002/arch.21609.

9. Roy S, Saha TT, Zou Z, Raikhel AS. Regulatory pathways controlling female insect reproduction. Annu Rev Entomol. 2018;63(1):489-511. https://doi. org/10.1146/annurev-ento-020117-043258.

10. Santos CG, Humann FC, Hartfelder K. Juvenile hormone signaling in insect oogenesis. Curr Opin Insect Sci. 2019;31:43-8. https://doi.org/10.1016/j.cois.2 018.07.010.

11. Truman JW. The evolution of insect metamorphosis. Curr Biol. 2019;29(23): R1252-r1268. https://doi.org/10.1016/j.cub.2019.10.009.

12. Jindra M, Palli SR, Riddiford LM. The juvenile hormone signaling pathway in insect development. Annu Rev Entomol. 2013;58(1):181-204. https://doi. org/10.1146/annurev-ento-120811-153700.

13. Kayukawa T, Nagamine K, Ito Y, Nishita Y, Ishikawa Y, Shinoda T. Krüppe homolog 1 inhibits insect metamorphosis via direct transcriptional repression of Broad-Complex, a pupal specifier gene. J Biol Chem. 2016; 291(4):1751-62. https://doi.org/10.1074/jbc.M115.686121.

14. Urena E, Chafino S, Manjon C, Franch-Marro X, Martin D. The occurrence of the holometabolous pupal stage requires the interaction between E93, Krüppel-Homolog 1 and Broad-Complex. PLoS Genet. 2016;12(5):e1006020. https://doi.org/10.1371/journal.pgen.1006020.

15. Belles X, Santos CG. The MEKRE93 (Methoprene tolerant-Krüppel homolog 1-E93) pathway in the regulation of insect metamorphosis, and the homology of the pupal stage. Insect Biochem Mol Biol. 2014;52:60-8. https://doi.org/10.1016/j.ibmb.2014.06.009.

16. Gujar H, Palli SR. Krüppel homolog 1 and E93 mediate Juvenile hormone regulation of metamorphosis in the common bed bug, Cimex lectularius. Sci Rep. 2016;6(1):26092. https://doi.org/10.1038/srep26092.

17. Kayukawa T, Jouraku A, Ito Y, Shinoda T. Molecular mechanism underlying juvenile hormone-mediated repression of precocious larval-adult metamorphosis. Proc Natl Acad Sci U S A. 2017;114(5):1057-62. https://doi. org/10.1073/pnas.1615423114.

18. Zhang T, Song W, Li Z, Qian W, Wei L, Yang Y, et al. Krüppel homolog 1 represses insect ecdysone biosynthesis by directly inhibiting the transcription of steroidogenic enzymes. Proc Natl Acad Sci U S A. 2018; 115(15):3960-5. https://doi.org/10.1073/pnas.1800435115.

19. Song J, Zhou S. Post-transcriptional regulation of insect metamorphosis and oogenesis. Cell Mol Life Sci. 2019;77(10):1893-909. https://doi.org/10.1007/ s00018-019-03361-5.

20. Jiang J, Xu Y, Lin X. Role of Broad-Complex (Br) and Krüppel homolog 1 (Krh1) in the ovary development of Nilaparvata lugens. Front Physiol. 2017;8: 1013. https://doi.org/10.3389/fphys.2017.01013.

21. Song J, Wu Z, Wang Z, Deng S, Zhou S. Krüppel-homolog 1 mediates juvenile hormone action to promote vitellogenesis and oocyte maturation in the migratory locust. Insect Biochem Mol Biol. 2014;52:94-101. https://doi. org/10.1016/j.ibmb.2014.07.001.

22. Tang $Y$, He H, Qu X, Cai Y, Ding W, Qiu L, et al. RNA interference-mediated knockdown of the transcription factor Krüppel homologue 1 suppresses vitellogenesis in Chilo suppressalis. Insect Mol Biol. 2020;29(2):183-92. https:// doi.org/10.1111/imb.12617.

23. Yue $Y$, Yang RL, Wang WP, Zhou QH, Chen EH, Yuan GR, et al. Involvement of Met and $\mathrm{Kr}$-h1 in $\mathrm{JH}$-mediated reproduction of female Bactrocera dorsalis (Hendel). Front Physiol. 2018;9:482. https://doi.org/10.3389/fphys.2018.00482

24. Zhang WN, Ma L, Liu C, Chen L, Xiao HJ, Liang GM. Dissecting the role of Krüppel homolog 1 in the metamorphosis and female reproduction of the cotton bollworm, Helicoverpa armigera. Insect Mol Biol. 2018;27(4):492-504. https://doi.org/10.1111/imb.12389.

25. Shin SW, Zou Z, Saha TT, Raikhel AS. bHLH-PAS heterodimer of methoprene-tolerant and Cycle mediates circadian expression of juvenile hormone-induced mosquito genes. Proc Natl Acad Sci U S A. 2012;109(41): 16576-81. https://doi.org/10.1073/pnas.1214209109.

26. Ojani R, Fu X, Ahmed T, Liu P, Zhu J. Krüppel homologue 1 acts as a repressor and an activator in the transcriptional response to juvenile 
hormone in adult mosquitoes. Insect Mol Biol. 2018;27(2):268-78. https:// doi.org/10.1111/imb.12370.

27. Saha TT, Roy S, Pei G, Dou W, Zou Z, Raikhel AS. Synergistic action of the transcription factors Krüppel homolog 1 and Hairy in juvenile hormone/ Methoprene-tolerant-mediated gene-repression in the mosquito Aedes aegypti. PLoS Genet. 2019;15(10):e1008443. https://doi.org/10.1371/journal. pgen.1008443.

28. Gujar H, Palli SR. Juvenile hormone regulation of female reproduction in the common bed bug, Cimex lectularius. Sci Rep. 2016;6(1):35546. https://doi. org/10.1038/srep35546.

29. Cui Y, Sui Y, Xu J, Zhu F, Palli SR. Juvenile hormone regulates Aedes aegypt Krüppel homolog 1 through a conserved E box motif. Insect Biochem Mol Biol. 2014;52:23-32. https://doi.org/10.1016/j.ibmb.2014.05.009.

30. Kayukawa T, Minakuchi C, Namiki T, Togawa T, Yoshiyama M, Kamimura M, et al. Transcriptional regulation of juvenile hormone-mediated induction of Krüppel homolog 1, a repressor of insect metamorphosis. Proc Natl Acad Sci U S A. 2012;109(29):11729-34. https://doi.org/10.1073/pnas.1204951109.

31. Wang Z, Yang L, Song J, Kang L, Zhou S. An isoform of Taiman that contains a PRD-repeat motif is indispensable for transducing the vitellogenic juvenile hormone signal in Locusta migratoria. Insect Biochem Mol Biol. 2017:82:31-40. https://doi.org/10.1016/j.ibmb.2017.01.009.

32. Lozano J, Kayukawa T, Shinoda T, Belles X. A role for Taiman in insect metamorphosis. PLoS Genet. 2014;10(10):e1004769. https://doi.org/10.1371/ journal.pgen.1004769.

33. Jindra M, Tumova S, Milacek M. A decade with the juvenile hormone receptor. In: Bittova L. Adv In Insect Phys: A decade with the juvenile hormone receptor; 2021.

34. George S, Gaddelapati SC, Palli SR. Histone deacetylase 1 suppresses Krüppel homolog 1 gene expression and influences juvenile hormone action in Tribolium castaneum. Proc Natl Acad Sci U S A. 2019:116(36):17759-64. https://doi.org/10.1073/pnas.1909554116.

35. Roy A, Palli SR. Epigenetic modifications acetylation and deacetylation play important roles in juvenile hormone action. BMC Genomics. 2018;19(1):934 https://doi.org/10.1186/s12864-018-5323-4

36. Belles X. MicroRNAs and the evolution of insect metamorphosis. Annu Rev Entomol. 2017;62(1):111-25. https://doi.org/10.1146/annurev-ento-031616034925

37. Lozano J, Montanez R, Belles X. MiR-2 family regulates insect metamorphosis by controlling the juvenile hormone signaling pathway. Proc Natl Acad Sci U S A. 2015;112(12):3740-5. https://doi.org/10.1073/pna S. 1418522112

38. Song J, Li W, Zhao H, Gao L, Fan Y, Zhou S. The microRNAs let-7 and miR278 regulate insect metamorphosis and oogenesis by targeting the juvenile hormone early-response gene Krüppel-homolog 1. Development. 2018;145: dev170670.

39. Jing $Y P$, An $H$, Zhang $\mathrm{S}$, Wang $\mathrm{N}$, Zhou S. Protein kinase $\mathrm{C}$ mediates juvenile hormone-dependent phosphorylation of $\mathrm{Na}(+) / \mathrm{K}(+)$-ATPase to induce ovarian follicular patency for yolk protein uptake. J Biol Chem. 2018;293(52): 20112-22. https://doi.org/10.1074/jbc.RA118.005692.

40. Liu P, Fu X, Zhu J. Juvenile hormone-regulated alternative splicing of the taiman gene primes the ecdysteroid response in adult mosquitoes. Proc Natl Acad Sci U S A. 2018;115(33):E7738-47. https://doi.org/10.1073/pnas.1 808146115.

41. Liu P, Peng HJ, Zhu J. Juvenile hormone-activated phospholipase C pathway enhances transcriptional activation by the methoprene-tolerant protein. Proc Natl Acad Sci U S A. 2015;112(15):E1871-9. https://doi.org/10.1 073/pnas.1423204112.

42. Liu W, Zhang FX, Cai MJ, Zhao WL, Li XR, Wang JX, et al. The hormone-dependent function of $\mathrm{Hsp90}$ in the crosstalk between 20hydroxyecdysone and juvenile hormone signaling pathways in insects is determined by differential phosphorylation and protein interactions. Biochim Biophys Acta. 1830;2013(11):5184-92. https://doi.org/10.1016/j. bbagen.2013.06.037

43. Ojani R, Liu P, Fu X, Zhu J. Protein kinase C modulates transcriptional activation by the juvenile hormone receptor methoprene-tolerant. Insect Biochem Mol Biol. 2016;70:44-52. https://doi.org/10.1016/j.ibmb.2 015.12.001.

44. Cai MJ, Liu W, Pei XY, Li XR, He HJ, Wang JX, et al. Juvenile hormone prevents 20-hydroxyecdysone-induced metamorphosis by regulating the phosphorylation of a newly identified broad protein. J Biol Chem. 2014; 289(38):26630-41. https://doi.org/10.1074/jbc.M114.581876.
45. lakoucheva LM, Radivojac P, Brown CJ, O'Connor TR, Sikes JG, Obradovic Z, et al. The importance of intrinsic disorder for protein phosphorylation. Nucleic Acids Res. 2004;32(3):1037-49. https://doi.org/10.1093/nar/gkh253.

46. Airas JM, Betz H, El Far O. PKC phosphorylation of a conserved serine residue in the $\mathrm{C}$-terminus of group III metabotropic glutamate receptors inhibits calmodulin binding. FEBS Lett. 2001;494(1-2):60-3. https://doi.org/1 0.1016/S0014-5793(01)02311-0

47. Liu QR, Zhang PW, Lin Z, Li QF, Woods AS, Troncoso J, et al. GBPI, a novel gastrointestinal- and brain-specific PP1-inhibitory protein, is activated by PKC and inactivated by PKA. Biochem J. 2004;377(1):171-81. https://doi. org/10.1042/bj20030128.

48. Boratko A, Csortos C. PKC mediated phosphorylation of TIMAP regulates PP1C activity and endothelial barrier function. Biochim Biophys Acta Mol Cell Res. 1864;2017(2):431-9. https://doi.org/10.1016/j.bbamcr.2016.12.001.

49. Xue Y, Ren J, Gao X, Jin C, Wen L, Yao X. GPS 2.0, a tool to predict kinasespecific phosphorylation sites in hierarchy. Mol Cell Proteomics. 2008;7(9): 1598-608. https://doi.org/10.1074/mcp.M700574-MCP200.

50. Truman JW, Riddiford LM. The origins of insect metamorphosis. Nature. 1999;401 (6752):447-52. https://doi.org/10.1038/46737.

51. Guo W, Wu Z, Yang L, Cai Z, Zhao L, Zhou S. Juvenile hormone-dependent Kazal-type serine protease inhibitor Greglin safeguards insect vitellogenesis and egg production. FASEB J. 2019;33(1):917-27. https://doi.org/10.1096/fj.2 01801068R.

52. Guo W, Wu Z, Song J, Jiang F, Wang Z, Deng S, et al. Juvenile hormonereceptor complex acts on $\mathrm{mcm} 4$ and $\mathrm{mcm} 7$ to promote polyploidy and vitellogenesis in the migratory locust. PLoS Genet. 2014;10(10):e1004702. https://doi.org/10.1371/journal.pgen.1004702.

53. de la Cruz J, Karbstein K, Woolford JL Jr. Functions of ribosomal proteins in assembly of eukaryotic ribosomes in vivo. Annu Rev Biochem. 2015;84(1): 93-129. https://doi.org/10.1146/annurev-biochem-060614-033917.

54. Mannervik M. Control of Drosophila embryo patterning by transcriptional co-regulators. Exp Cell Res. 2014;321 (1):47-57. https://doi.org/10.1016/j. yexcr.2013.10.010

55. Qiu J, He Y, Zhang J, Kang K, Li T, Zhang W. Discovery and functional identification of fecundity-related genes in the brown planthopper by largescale RNA interference. Insect Mol Biol. 2016;25(6):724-33. https://doi.org/1 $0.1111 / \mathrm{imb} .12257$

56. Eusebio N, Tavares L, Pereira PS. CtBP represses Dpp-dependent Mad activation during Drosophila eye development. Dev Biol. 2018;442(1):188-98. https://doi.org/10.1016/j.ydbio.2018.07.018.

57. Xu J, Roy A, Palli SR. CREB-binding protein plays key roles in juvenile hormone action in the red flour beetle, Tribolium Castaneum. Sci Rep. 2018: 8(1):1426. https://doi.org/10.1038/s41598-018-19667-6.

58. Fernandez-Nicolas A, Belles X. CREB-binding protein contributes to the regulation of endocrine and developmental pathways in insect hemimetabolan pre-metamorphosis. Biochim Biophys Acta. 1860;2016(3): 508-15. https://doi.org/10.1016/j.bbagen.2015.12.008.

59. Li YX, Wang D, Zhao WL, Zhang JY, Kang XL, Li YL, et al. Juvenile hormone induces methoprene-tolerant 1 phosphorylation to increase interaction with Taiman in Helicoverpa armigera. Insect Biochem Mol Biol. 2021;130:103519. https://doi.org/10.1016/j.ibmb.2021.103519.

60. Kim K, Albishi NM, Palli SR. Identification of juvenile hormone-induced posttranslational modifications of methoprene tolerant and Krüppel homolog 1 in the yellow fever mosquito, Aedes aegypti. J Proteomics. 2021; 242:104257. https://doi.org/10.1016/j.jprot.2021.104257.

61. Brayer KJ, Segal DJ. Keep your fingers off my DNA: protein-protein interactions mediated by $\mathrm{C} 2 \mathrm{H} 2$ zinc finger domains. Cell Biochem Biophys. 2008;50(3):111-31. https://doi.org/10.1007/s12013-008-9008-5.

62. Gamsjaeger R, Liew CK, Loughlin FE, Crossley M, Mackay JP. Sticky fingers: zinc-fingers as protein-recognition motifs. Trends Biochem Sci. 2007;32(2): 63-70. https://doi.org/10.1016/j.tibs.2006.12.007.

63. Saha TT, Shin SW, Dou W, Roy S, Zhao B, Hou Y, et al. Hairy and Groucho mediate the action of juvenile hormone receptor Methoprene-tolerant in gene repression. Proc Natl Acad Sci U S A. 2016;113(6):E735-43. https://doi. org/10.1073/pnas.1523838113.

64. Mao Y, Li Y, Gao H, Lin X. Krüppel homologue 1 interacts directly with Hairy and regulates ecdysis in the brown planthopper. Insect Mol Biol. 2020;29(3): 293-300. https://doi.org/10.1111/imb.12635.

65. Chahrour M, Jung SY, Shaw C, Zhou X, Wong ST, Qin J, et al. MeCP2, a key contributor to neurological disease, activates and represses transcription. Science. 2008;320(5880):1224-9. https://doi.org/10.1126/science.1153252. 
66. Evans PM, Zhang W, Chen X, Yang J, Bhakat KK, Liu C. Krüppel-like factor 4 is acetylated by p300 and regulates gene transcription via modulation of histone acetylation. J Biol Chem. 2007;282(47):33994-4002. https://doi.org/1 0.1074/jbc.M701847200.

67. Martinez-Montanes F, Rienzo A, Poveda-Huertes D, Pascual-Ahuir A, Proft M. Activator and repressor functions of the Mot3 transcription factor in the osmostress response of Saccharomyces cerevisiae. Eukaryot Cell. 2013;12(5): 636-47. https://doi.org/10.1128/EC.00037-13.

68. Oswald F, Kovall RA. CSL-associated corepressor and coactivator complexes. Adv Exp Med Biol. 2018;1066:279-95. https://doi.org/10.1007/978-3-31989512-3_14.

69. Richier B, Michard-Vanhee C, Lamouroux A, Papin C, Rouyer F. The clockwork orange Drosophila protein functions as both an activator and a repressor of clock gene expression. J Biol Rhythms. 2008;23(2):103-16. https://doi.org/10.1177/0748730407313817.

70. Tetel MJ, Auger AP, Charlier TD. Who's in charge? Nuclear receptor coactivator and corepressor function in brain and behavior. Front Neuroendocrinol. 2009: 30(3):328-42. https:/doi.org/10.1016/j.yfrne.2009.04.008.

71. Wu Z, Guo W, Yang L, He Q, Zhou S. Juvenile hormone promotes locust fat body cell polyploidization and vitellogenesis by activating the transcription of Cdk6 and E2f1. Insect Biochem Mol Biol. 2018;102:1-10. https://doi.org/1 0.1016/j.ibmb.2018.09.002.

\section{Publisher's Note}

Springer Nature remains neutral with regard to jurisdictional claims in published maps and institutional affiliations.

Ready to submit your research? Choose BMC and benefit from:

- fast, convenient online submission

- thorough peer review by experienced researchers in your field

- rapid publication on acceptance

- support for research data, including large and complex data types

- gold Open Access which fosters wider collaboration and increased citations

- maximum visibility for your research: over $100 \mathrm{M}$ website views per year

At $\mathrm{BMC}$, research is always in progress.

Learn more biomedcentral.com/submissions 